\title{
Hydrogen Sulfide Abrogates Hemoglobin-Lipid Interaction in Atherosclerotic Lesion
}

\author{
László Potor, ${ }^{1,2}$ Péter Nagy, ${ }^{3}$ Gábor Méhes, ${ }^{4}$ Zoltán Hendrik $\mathbb{D}^{1,},{ }^{1,4}$ Viktória Jeney (D), \\ Dávid Pethö, ${ }^{5}$ Anita Vasas, ${ }^{3,6}$ Zoltán Pálinkás, ${ }^{3}$ Enikő Balogh ${ }^{1},{ }^{5}$ Ágnes Gyetvai, ${ }^{1}$ \\ Matthew Whiteman, ${ }^{7}$ Roberta Torregrossa, ${ }^{7}$ Mark E. Wood, ${ }^{8}$ Sándor Olvasztó, ${ }^{9}$ Péter Nagy, ${ }^{9}$ \\ György Balla, ${ }^{1,2}$ and József Balla (iD ${ }^{5}$
}

\author{
${ }^{1}$ HAS-UD Vascular Biology and Myocardial Pathophysiology Research Group, Hungarian Academy of Sciences, \\ Debrecen 4012, Hungary \\ ${ }^{2}$ Department of Pediatrics, Faculty of Medicine, University of Debrecen, Debrecen 4012, Hungary \\ ${ }^{3}$ Department of Molecular Immunology and Toxicology, National Institute of Oncology, Budapest 1122, Hungary \\ ${ }^{4}$ Department of Pathology, Faculty of Medicine, University of Debrecen, Debrecen 4012, Hungary \\ ${ }^{5}$ Division of Nephrology, Department of Medicine, Faculty of Medicine, University of Debrecen, Debrecen 4012, Hungary \\ ${ }^{6}$ Department of Inorganic and Analytical Chemistry, University of Debrecen, Debrecen 4032, Hungary \\ ${ }^{7}$ University of Exeter Medical School, Exeter, UK \\ ${ }^{8}$ College of Life and Environmental Sciences, University of Exeter, Exeter, UK \\ ${ }^{9}$ Division of Vascular Surgery, Department of Surgery, Faculty of Medicine, University of Debrecen, Debrecen 4012, Hungary
}

Correspondence should be addressed to József Balla; balla@belklinika.com

Received 2 August 2017; Revised 6 November 2017; Accepted 14 November 2017; Published 21 January 2018

Academic Editor: Kota V. Ramana

Copyright (C) 2018 László Potor et al. This is an open access article distributed under the Creative Commons Attribution License, which permits unrestricted use, distribution, and reproduction in any medium, provided the original work is properly cited.

\begin{abstract}
The infiltration of red blood cells into atheromatous plaques is implicated in atherogenesis. Inside the lesion, hemoglobin (Hb) is oxidized to ferri- and ferrylHb which exhibit prooxidant and proinflammatory activities. Cystathione gamma-lyase- (CSE-) derived $\mathrm{H}_{2} \mathrm{~S}$ has been suggested to possess various antiatherogenic actions. Expression of CSE was upregulated predominantly in macrophages, foam cells, and myofibroblasts of human atherosclerotic lesions derived from carotid artery specimens of patients. A similar pattern was observed in aortic lesions of apolipoprotein E-deficient mice on high-fat diet. We identified several triggers for inducing CSE expression in macrophages and vascular smooth muscle cells including heme, ferrylHb, plaque lipids, oxidized low-density lipoprotein, tumor necrosis factor- $\alpha$, and interleukin- $1 \beta$. In the interplay between hemoglobin and atheroma lipids, $\mathrm{H}_{2} \mathrm{~S}$ significantly mitigated oxidation of $\mathrm{Hb}$ preventing the formation of ferrylHb derivatives, therefore providing a novel function as a heme-redox-intermediate-scavenging antioxidant. By inhibiting Hb-lipid interactions, sulfide lowered oxidized $\mathrm{Hb}$-mediated induction of adhesion molecules in endothelium and disruption of endothelial integrity. Exogenous $\mathrm{H}_{2} \mathrm{~S}$ inhibited heme and $\mathrm{Hb}$-mediated lipid oxidation of human atheroma-derived lipid and human complicated lesion. Our study suggests that the $\mathrm{CSE} / \mathrm{H}_{2} \mathrm{~S}$ system represents an atheroprotective pathway for removing or limiting the formation of oxidized $\mathrm{Hb}$ and lipid derivatives in the atherosclerotic plaque.
\end{abstract}

\section{Introduction}

Atherosclerosis-related morbidity and mortality are closely associated with the presence of vulnerable plaques and complicated lesions [1-3]. These lesions contain products of lipid peroxidation such as lipid hydroperoxides, aldehydes and carbonyls, calcium, and redox active iron [4]. Vascular lesions are called complicated where due to a disruption of the atheromatous plaque, infiltration of red blood cells (RBCs) are visualized inside the lesion [2]. It was recently shown by Michel et al. that the neovascularization could be observed from the adventitia through the media into the 
plaque [5]. Often, RBCs infiltrate these lesions as a consequence of leaky neovessels or intraplaque hemorrhage $[3,6]$. It was shown that part of the damaged RBCs are taken up by macrophages via erythrophagocytosis and degraded in the lysosome. The generated iron could be exocytosed from the macrophages to the extracellular space and induce oxidation of the LDL and its uptake by macrophages [7-9]. It was shown that invading RBCs lyse and release hemoglobin $(\mathrm{Hb})$ inside the plaque and react with the surrounding plaque lipids [10-12]. In the reactions between $\mathrm{Hb}$ and plaque lipids, different oxidized $\mathrm{Hb}$ derivatives are formed including metHb $\left(\mathrm{Fe}^{3+}\right)$ and ferrylHb $\left(\mathrm{Fe}^{4+}=\mathrm{O}^{2-}\right)$ species [10-12]. Furthermore, the ferryl form is unstable and triggers an electron transfer from proximal amino acids of the globin chain to iron, resulting in globin radical formation. Termination reactions of globin radicals yield covalently cross-linked $\mathrm{Hb}$ multimers which are present in human complicated atherosclerotic lesions $[10,12]$.

Oxidized $\mathrm{Hb}$ species exert different prooxidant and proinflammatory effects. Both metHb and ferrylHb (we herein use the term ferrylHb to refer to the sum of all those oxidized $\mathrm{Hb}$ species in which production the unstable $\mathrm{Fe}^{4+}$ oxidation state has been involved) sensitize vascular endothelial cells to oxidant-mediated killing $[11,13]$ and induce lipid peroxidation via the release of heme and redox active iron $[11,14]$. Oxidized $\mathrm{Hb}$ has been recently shown to provoke the rearrangement of F-actin cytoskeleton and subsequently the formation of intercellular gaps in endothelium in vitro and facilitate the adherence of monocytes to the endothelium through the induction of adhesion molecules: vascular cell adhesion molecule-1 (VCAM-1), intercellular adhesion molecule-1 (ICAM-1), and E-selectin [11, 15].

Hydrogen sulfide $\left(\mathrm{H}_{2} \mathrm{~S}\right)$, recently proposed as the newest member of the gaseous mediators' family, has been shown to possess antiatherogenic effects in different animal models (reviewed in [16]). Wang et al. previously reported that atherosclerotic lesion formation is inhibited by sodium hydrosulfide ( $\mathrm{NaSH}$, an inorganic source of sulfide) in apolipoprotein $\mathrm{E}$ knockout mice $\left(\mathrm{ApoE}^{-/-}\right)$, whereas pharmacological inhibition of cystathionine gamma-lyase (CSE), a key enzyme of $\mathrm{H}_{2} \mathrm{~S}$ generation in the vasculature, resulted in accelerated plaque formation [17]. A more recent and robust study by Mani et al. using CSE knockout mice showed decreased vascular production of $\mathrm{H}_{2} \mathrm{~S}$ accompanied by accelerated atherosclerotic plaque progression compared to wild-type animal highlighting the central importance of CSE and $\mathrm{H}_{2} \mathrm{~S}$ as endogenous vasoprotective mediators [18].

Based on these observations, we aimed to investigate whether hydrogen sulfide inhibits hemoglobin-lipid interactions in atherosclerotic lesions and alter subsequent endothelial cell reactions. We also determined how atherogenesis influenced the vascular expression of CSE and identified pathophysiological modulators of CSE expression.

\section{Materials and Methods}

2.1. Materials. All chemicals were analytical reagent grade or better and purchased from Sigma-Aldrich (St. Louis, MO, USA). The sulfide donor molecules used in this
study-GYY4137 (P-(4-methoxyphenyl)-P-4-morpholinylphosphinodithioic acid morpholine salt), AP67 (4-methoxyphenyl)(pyrrolidin-1-yl)phosphinodithioc acid), and AP72 (4-methoxyphenyl)(piperidin-1-yl)phosphinodithioc acid)were synthesized in-house $[19,20]$. Sulfide stock solutions were prepared fresh daily in water and used immediately.

2.2. Human Tissue Samples. For the study, we used 54 carotid artery specimens collected from 54 human patients who underwent carotid endarterectomy surgery. 15 samples were used for immunohistochemistry analysis, and 39 carotid arteries were used for the in vitro experiments. Written informed consent was received from the participants according to the Declaration of Helsinki. A pathologist examined the samples and classified them according to AHA guidelines. Type I (healthy), IV (atheromatous), and VI (complicated) lesions were selected for the study.

2.3. Mice. All the animal experiments were approved by the guidelines from Directive 2010/63/EU of the European Parliament on the protection of animals used for scientific purposes. Animal experiments performed in this study were approved by the Scientific and Research Ethics Committee of the Scientific Council of Health of the Hungarian Government under the registration number DE MÁB/157-5/2010 and are reported in accordance with the ARRIVE guidelines. C57BL/6 ApoE ${ }^{-1-}$ mice were maintained at the University of Debrecen under specific pathogen-free conditions in accordance with guidelines from Institutional Ethical Committee. To induce atherosclerotic plaque formation, standard chow diet was changed to atherogenic diet (15\% fat, $1.25 \%$ cholesterol, ssniff-Spezialdiäten $\mathrm{GmbH}$, Soest, Germany) at the age of 8 weeks. Mice were randomly divided into three groups, and parallel with the atherogenic diet, mice were injected intraperitoneally with $\mathrm{NaSH}(56 \mu \mathrm{mol} / \mathrm{kg}$ body weight; $N=9)$, PPG $(50 \mathrm{mg} / \mathrm{kg}, N=5)$, or vehicle (PBS; $N=21$ ) every other day as previously described [17]. Aortas were harvested after 8 weeks of treatment. All mice were euthanized by predictable and controllable administering slow-fill compressed $\mathrm{CO}_{2}$ asphyxiation.

2.4. Cell Culture. Human aortic endothelial cells (HAoECs) (PromoCell, Heidelberg, Germany) were cultured in medium 199 containing 15\% FBS, antibiotics, L-glutamine, sodium pyruvate, and EC growth factor as described previously. HAoECs were used at passages 2 and 3 within 2 days postconfluence. Human aortic smooth muscle cells (HASMCs) (PromoCell, Heidelberg, Germany) were cultured in DMEM supplemented with $10 \%$ FBS, L-glutamine, sodium pyruvate, and antibiotics. RAW264.7 murine macrophages (ATCC) were grown in RPMI supplemented with L-glutamine, sodium pyruvate, and antibiotics.

2.5. Immunohistochemistry. Immunohistochemistry from the carotid arteries was performed on formalin-fixed, paraffin-embedded tissue sections. $4 \mu \mathrm{m}$ slides were then deparaffinated using xylol and ethanol.

Samples were incubated with the anti-CSE primary monoclonal antibody (12217-1-AP Proteintech, Chicago, IL, USA) at a dilution of $1: 200$. Other slides of the same 
samples were incubated with antihemoglobin (clone: goat polyclonal HRP (ab19362), Proteintech Group, Rosemont, IL 60018, USA) primary monoclonal antibody at a dilution of $1: 100$; with HO-1 (clone: rabbit polyclonal (10701-1AP), Proteintech Group, Rosemont, IL 60018, USA) primary monoclonal antibody at a dilution of $1: 200$; and with HO-2 (clone: rabbit polyclonal (14817-1-AP), Proteintech Group, Rosemont, IL 60018, USA) primary monoclonal antibody at a dilution of $1: 400$. Specific antibody binding was visualized by the Dako EnVision FLEX/HRP and FLEX DAB3 Chromogen detection system (Dako, Glostrup, Danmark) followed by hematoxylin counterstaining and coverage. The intensity and distribution of protein immunostaining were assessed by light microscopy (Leica DM2500 microscope, DFC 420 camera and Leica Application Suite V3 software, Leica).

2.6. Dual Immunohistochemistry. Dual IHC was done as follows. The CSE enzyme was specifically labeled with a polyclonal antibody clone (12217-1-AP, Proteintech, Manchester, UK; dilution 1:100) and detected by the EnVision Flex HRP/DAB+ (brown color) procedure. This was followed by a second incubation procedure with either of the primary antibodies (CD4, CD34, or SMA) which were detected by the Flex HRP system using the violet VIP chromogen (Vector Laboratories, Burlingame, CA) as a substrate. This setting clearly differentiated the DABrelated brown staining and the VIP-related violet staining even within the same cells by light microscopy. Methylgreen solution (Vector Laboratories, Burlingame, CA) was used to counterstain unlabeled cell nuclei of any of the tissue constituents.

2.7. Hemoglobin Preparation. Hb of different redox states, that is, $\left(\mathrm{Fe}^{2+}\right)$ oxyHb, $\left(\mathrm{Fe}^{3+}\right)$ metHb, and ferrylHb, were prepared as described [15]. Briefly, $\mathrm{Hb}$ was isolated from fresh blood drawn from healthy volunteers using ion-exchange chromatography on a DEAE Sepharose CL-6B column. $\mathrm{MetHb}$ was generated by incubation $\left(30 \mathrm{~min}, 25^{\circ} \mathrm{C}\right)$ of purified $\mathrm{Hb}$ with a 1.5 -fold molar excess of $\mathrm{K}_{3} \mathrm{Fe}(\mathrm{CN})_{6}$ over heme. FerrylHb was obtained by incubation $\left(1 \mathrm{~h}, 37^{\circ} \mathrm{C}\right)$ of $\mathrm{Hb}$ with a $10: 1$ ratio of $\mathrm{H}_{2} \mathrm{O}_{2}$ to heme. After oxidation, both metHb and ferrylHb were dialyzed against saline (3 times for 3 hours at $4^{\circ} \mathrm{C}$ ) and concentrated using Amicon Ultra centrifugal filter tubes (10,000 MWCO, Millipore Corp., Billerica, MA, USA). Aliquots were snap-frozen in liquid nitrogen, and stored at $-80^{\circ} \mathrm{C}$ until use. The purity of each $\mathrm{Hb}$ preparation was evaluated by SDS-PAGE followed by silver staining. The purity of $\mathrm{Hb}$ preparations was above $99.9 \%$. Hb concentrations were calculated as described by Winterbourn [21].

2.8. Isolation and Oxidation of LDL. LDL was isolated from the plasma of EDTA-anticoagulated venous blood of healthy volunteers by gradient ultracentrifugation (Beckman Coulter Inc., Brea, CA, USA). The density of plasma was adjusted to $1.3 \mathrm{~g} / \mathrm{mL}$ with $\mathrm{KBr}$ and a two-layer gradient was made in a Quick-Seal ultracentrifuge tube by layering saline on $10 \mathrm{~mL}$ plasma. Ultracentrifugation was performed at $302,000 \mathrm{~g}$ for 2 hours at $4^{\circ} \mathrm{C}$ (VTi 50.2 rotor). LDL samples were kept at $-70^{\circ} \mathrm{C}$ until use, and the protein concentration was determined by Pierce BCA protein assay kit (Pierce Biotechnology, Rockford, IL, USA). LDL oxidation was carried out at $37^{\circ} \mathrm{C}$ in a reaction mixture containing $\mathrm{LDL}(200 \mu \mathrm{g} / \mathrm{mL})$, heme $(5 \mu \mathrm{mol} / \mathrm{L})$, and $\mathrm{H}_{2} \mathrm{O}_{2}(75 \mu \mathrm{mol} / \mathrm{L})$.

2.9. Oxidation of LDL. LDL $(200 \mu \mathrm{g} / \mathrm{mL})$ was oxidized with heme $(5 \mu \mathrm{mol} / \mathrm{L})$ and $\mathrm{H}_{2} \mathrm{O}_{2}(75 \mu \mathrm{mol} / \mathrm{L})$ in the presence or absence of the sulfide donors NaSH, GYY4137, AP67, and AP72 at concentrations of 20 and $200 \mu \mathrm{mol} / \mathrm{L}$ at $37^{\circ} \mathrm{C}$. Conjugated diene formation was monitored continuously for 1 hour at $234 \mathrm{~nm}$. Delta OD234 nm was calculated by subtracting optical density measured at the 0 time point from optical density measured at 1 hour. The formations of lipid hydroperoxides $(\mathrm{LOOH})$ and thiobarbituric acid reactive substances (TBARS) were measured at 60 minutes following the initiation of lipid peroxidation. The method of Wolf was used to evaluate $\mathrm{LOOH}$ content in the LDL samples [14]. For the TBARS measurement, $50 \mu \mathrm{L}$ of a $200 \mu \mathrm{g}$ protein/mL LDL sample was mixed with $100 \mu \mathrm{L}$ of thiobarbituric acid reagent $(0.375 \mathrm{~g}$ 2-thiobarbituric acid, $2.08 \mathrm{~mL} \mathrm{HCl}$, and $15 \mathrm{~mL} 10 \%$ trichloroacetic acid to a final volume of $100 \mathrm{~mL}$ ). After heating at $90^{\circ} \mathrm{C}$ for 20 minutes, the samples were cooled and extracted with $200 \mu \mathrm{L}$ n-butanol. The upper phase was measured spectrophotometrically at $532 \mathrm{~nm}$. Results were calculated using a molar extinction coefficient of $1.56 \times 10^{5} \mathrm{M}^{-1} \cdot \mathrm{cm}^{-1}$ and are expressed as nmol TBARs/mg protein.

2.10. Plaque Lipid Oxidation. Lipids were extracted from human carotid artery plaques as described previously [13]. Plaque lipids $(0.5 \mathrm{mg} / \mathrm{mL})$ were incubated with $\mathrm{Hb}$ $(100 \mu \mathrm{mol} / \mathrm{L})$ in the presence or absence of the sulfide donors NaSH, GYY4137, AP67, and AP72 at $200 \mu \mathrm{mol} / \mathrm{L}$ concentration for 4 days at $37^{\circ} \mathrm{C}$. In other cases, complicated lesions containing intraplaque hemorrhage were homogenized in saline. These samples $(0.5 \mathrm{mg} / \mathrm{mL})$ were incubated at $37^{\circ} \mathrm{C}$ for 3 days in the presence or absence of the sulfide donors NaSH, GYY4137, AP67, and AP72. Lipid peroxidation was assessed by measuring LOOH and TBARs.

2.11. Hb Oxidation and Detection of Covalently Cross-Linked $\mathrm{Hb}$ Species. Purified $\mathrm{Hb}(5 \mu \mathrm{mol} / \mathrm{L}$ heme) was incubated with $\mathrm{H}_{2} \mathrm{O}_{2}(25 \mu \mathrm{mol} / \mathrm{L})$ or oxidized LDL ( $50 \mu \mathrm{g}$ protein $/ \mathrm{mL}$ ) in the presence or absence of the sulfide donors NaSH, GYY4137, $\mathrm{AP} 67$, and AP72 at $37^{\circ} \mathrm{C}$ for 1 hour. For the detection of the covalently cross-linked $\mathrm{Hb}$ species, $0.5 \mu \mathrm{g}$ of $\mathrm{Hb}$ samples were applied to $12.5 \%$ SDS-PAGE gels. After electrophoresis, proteins were transferred to a nitrocellulose membrane (Amersham Biosciences Corp., Piscataway, NJ, USA) and $\mathrm{Hb}$ was identified using an HRP-conjugated goat anti-human $\mathrm{Hb}$ polyclonal antibody (ab19362-1 Abcam, Cambridge, UK) at a dilution of $1: 15,000$.

2.12. Stopped-Flow Spectrophotometry. Kinetic measurements were performed with a sequential stopped-flow apparatus (DX-18 MV, Applied Photophysics Ltd., Leatherhead, UK) using a $150 \mathrm{~W}$ Xe arc lamp. The reactions were followed at $\lambda=406,425,570$, and $620 \mathrm{~nm}$. All kinetic traces were collected in $20 \mathrm{mmol} / \mathrm{L}$ phosphate buffer at $\mathrm{pH} 7.40$ at 
$25^{\circ} \mathrm{C}$. At least 3 kinetic runs were made and averaged at each concentration to establish the corresponding kinetic traces.

2.13. Endothelial Cell Cytotoxicity Assay. LDL $(200 \mu \mathrm{g} / \mathrm{mL})$ was oxidized with heme $(5 \mu \mathrm{mol} / \mathrm{L})$ and $\mathrm{H}_{2} \mathrm{O}_{2}(75 \mu \mathrm{mol} / \mathrm{L})$. Oxidized LDL was incubated at $37^{\circ} \mathrm{C}$ overnight with the sulfide donors NaSH, GYY4137, AP67, and AP72 at concentrations of 20 and $200 \mu \mathrm{mol} / \mathrm{L}$. Confluent HAoECs grown in 96well tissue culture plates were washed twice with PBS and exposed to oxLDL samples for 6 hours. Cell viability was assessed by MTT assay as described previously [22].

2.14. Endothelial Cell Monolayer Integrity Assay. Electric cell substrate impedance sensing method was used to measure endothelial monolayer integrity. HAoECs were cultured on 8-well electrode arrays (8W10E, Applied BioPhysics Inc., Troy, NY, USA). Upon confluence, cells were challenged with $\mathrm{Hb}(10 \mu \mathrm{mol} / \mathrm{L})$ oxidized with $\mathrm{H}_{2} \mathrm{O}_{2}(50 \mu \mathrm{mol} / \mathrm{L})$ in the presence of sulfide donor molecules at the concentration of $200 \mu \mathrm{mol} / \mathrm{L}$. The complex impedance spectrum was monitored with an ECIS Zøinstrument (Applied BioPhysics Inc., Troy, NY, USA) for 3 hours in every minute. Intercellular gap formation was calculated based on the difference between monolayer resistance at $4000 \mathrm{~Hz}$ at the 0 time point and 3 hours. In other experiments, HAoECs were treated with $\mathrm{Hb}$ $(20 \mu \mathrm{mol} / \mathrm{L})$ oxidized with plaque lipids $(400 \mu \mathrm{g} / \mathrm{mL})$ in the presence of sulfide donor molecules $(200 \mu \mathrm{mol} / \mathrm{L})$ and impedance spectrum was monitored for 12 hours. Intercellular gap formation was calculated based on the difference between monolayer resistance at $4000 \mathrm{~Hz}$ at the 0 time point and 12 hours.

2.15. Western Blot. The cells were cultured in 6-well plates, and upon reaching the confluence, the cells were treated with different triggers. After 8 hours of treatment, the cells were solubilized in protein lysis buffer containing $10 \mathrm{mmol} / \mathrm{L}$ Tris-HCl, $5 \mathrm{mmol} / \mathrm{L}$ EDTA, $150 \mathrm{mmol} / \mathrm{L} \mathrm{NaCl}$ (pH 7.2), $1 \%$ Triton X-100, 0.5\% Nonidet P-40, and protease inhibitors (Complete Mini, F. Hoffmann-La Roche Ltd., Basel, Switzerland). In other experiments, tissue samples were homogenized under liquid nitrogen and solubilized in protein lysis buffer. Proteins $(10-20 \mu \mathrm{g})$ were applied to $12.5 \%$ SDSPAGE gels. After electrophoresis, proteins were transferred to a nitrocellulose membrane (Amersham Biosciences Corp., Piscataway, NJ, USA). Proteins were identified using the following antibodies: mouse anti-human HO-1 antibody (Calbiochem, San Diego, CA, USA, 374087, dilution $1: 2500$ ), rabbit anti-human HO-2 antibody (Proteintech, Chicago, IL, USA, 14817-1-AP), rabbit anti-human CSE antibody (Proteintech, Chicago, IL, USA, 12217-1-AP, dilution 1:1000), rabbit anti-human VCAM-1 (Santa Cruz Biotechnology Inc., Dallas, TX, USA, sc8304, dilution $1: 200$ ), mouse anti-human GAPDH (Novus Biologicals, Littleton, CO, USA NB-300-221, dilution 1:1000), antirabbit IgG HRP-conjugate (GE Healthcare Life Sciences, Piscataway, NJ, USA, NA934, dilution $1: 15,000)$, and anti-mouse IgG HRP-conjugate (GE Healthcare Life Sciences, Piscataway, NJ, USA, NA931, dilution 1:15,000). Antigen-antibody complex was detected by a horseradish peroxidase chemiluminescence system according to the manufacturer's instructions (GE Healthcare Life Sciences, Piscataway, NJ, USA). Quantification was performed using video densitometry (AlphaDigiDoc RT, Alpha Innotech Corp., San Leandro, CA, USA).

2.16. Quantitative Real-Time PCR (qRT-PCR). ApoE ${ }^{-/-}$mice were intraperitoneally injected with $\mathrm{NaSH}(56 \mu \mathrm{mol} / \mathrm{kg}$ body weight) or vehicle (PBS) in every other day over 8 weeks. Parallel with the treatment, the mice were fed with atherogenic diet. Control mice were fed with standard chow diet. After, the mice were sacrificed and aortas were harvested. Total RNA was isolated using RNAzol STAT-60 according to the manufacturer's instructions (cat. number Tl-4120, TEL-TEST Inc., Friendswood, TX, USA). RNA concentration was measured with NanoDropTM 2000c spectrophotometer (cat. number S06497c, Thermo Scientific Inc., Waltham, MA, USA). After that, cDNA synthesis was performed using a high-capacity cDNA kit (cat. number 43688-13, Applied Biosystems, Foster City, CA). We used real-time PCR technique for quantification of mRNA levels of HO-1 (Mm00516005_m1, Thermo Fisher Scientific Inc.) and beta-actin (Mm02619580_g1, Thermo Fisher Scientific Inc.). TaqMan Universal PCR Master Mix was purchased from Applied Biosystems (cat. number 4269510, Applied Biosystems, Foster City, CA). Finally, we performed TaqMan quantitative PCR $\left(40\right.$ cycles at $95^{\circ} \mathrm{C}$ for $15 \mathrm{sec}$. and $60^{\circ} \mathrm{C}$ for 1 min.) in 96-well plates with the Bio-Rad CFX96 (Bio-Rad Laboratories Inc., Hercules, California, USA) detection system. Results were expressed as mRNA expression normalized to beta-actin.

2.17. Determination of Sulfide Level from Tissue with Zinc Precipitation Assay. Sulfide levels were measured with zinc precipitation method based on a method developed by Gilboa-Garber [23] and modified by Ang et al. [24]. The human carotid artery was homogenized under liquid nitrogen in $7.4 \mathrm{pH}$ PBS and was sonicated. After that, the sample was centrifuged at $12,000 \mathrm{~g}$ for $15 \mathrm{~min}$ and the lipid-free clear supernatant was collected. $200 \mu \mathrm{L}$ sample was mixed with $350 \mu \mathrm{L} 1 \%$ zinc acetate and $50 \mu \mathrm{L} 1.5 \mathrm{~mol} / \mathrm{L}$ sodium hydroxide and incubated for 60 minutes on a shaker. Incubation step was followed by centrifugation at $2000 \mathrm{~g}$ for 5 minutes to pellet the generated zinc sulfide. The supernatant was then removed, and the pellet washed with $1 \mathrm{~mL}$ of distilled water by vortexing extensively, followed by centrifugation at $2000 \mathrm{~g}$ for 5 minutes. The supernatant was then aspirated off and the pellet reconstituted with $160 \mu \mathrm{L}$ of distilled water and mixed with $40 \mu \mathrm{L}$ of premixed dye $(20 \mu \mathrm{L}$ of $20 \mathrm{mmol} / \mathrm{L}$ dimethyl-p-phenylenediamine dihydrochloride (NNDP) in $7.2 \mathrm{~mol} / \mathrm{L}$ hydrochloric acid $(\mathrm{HCl})$ and $20 \mu \mathrm{L}$ of $30 \mathrm{mmol} / \mathrm{L}$ iron(III) chloride $\left(\mathrm{FeCl}_{3}\right)$ in $\left.1.2 \mathrm{~mol} / \mathrm{L} \mathrm{HCl}\right)$. After $10 \mathrm{~min}$, the absorbance of the generated methylene blue $(\mathrm{MB})$ was measured with spectrophotometer at $667 \mathrm{~nm}$. Since during the reaction $1 \mathrm{~mol} / \mathrm{L} \mathrm{MB}$ formed from $1 \mathrm{~mol} / \mathrm{L}$ sulfide, the concentration was determined by the MB's extinction coefficient $\left(30,200 \mathrm{M}^{-1} \cdot \mathrm{cm}^{-1}\right)$. Samples were normalized for protein concentration. 
2.18. Experimental Units. " $N$ " represents the number of tissue samples used in each group. " $n$ " denotes the number of replications of the independent results.

2.19. Study Approval. Collection of carotid artery plaques from patients who underwent carotid endarterectomy surgery was approved by the Scientific and Research Ethics Committee of the Scientific Council of Health of the Hungarian Government under the registration number of DE OEC RKEB/IKEB 3712-2012.

2.20. Statistics. Data were analyzed by GraphPad Prism 5.02 software (GraphPad Software Inc., 7825 Fay Avenue, Suite 230 La Jolla, CA 92037). All statistics data are expressed as mean \pm sem. Differences in means were analyzed by Student's $t$-test or one-way ANOVA with Dunnett's post test as appropriate. $p<0.05$ was considered significant.

\section{Results}

3.1. CSE Is Upregulated in Human and Mouse Atheromatous Plaques. To investigate whether CSE expression changes during atherogenesis, we performed both immunostainings of human carotid artery specimens and Western blotting. Western blot analysis of human vessel samples revealed that atheromatous lesions exhibit the higher content of CSE as compared to the healthy artery, or complicated lesions (Figure 1(a), lower panels). Localization of CSE by immunostaining (Figure 1(a), upper panels) demonstrated that CSE was highly expressed in macrophages, and foam cells of atheromatous plaque as well as in macrophages and foam cells of complicated lesions showing visible evidence of intraplaque hemorrhage (Figure 1(a), upper panel). For better visibility, we present same histological pictures with higher magnification as Supplementary Figure 1. We found that CSE-positive cells were more common in the atheroma compared to the complicated lesions. To evaluate CSE expression more accurately in different cell types of human samples, we performed double staining with cellular markers for macrophages, endothelial cells, and smooth muscle cells (Figure 2). Double immunohistochemistry revealed tissue macrophages (violet) presenting CSE expression (brown color) in complicated lesions (upper panels). Endothelium (middle panels, violet) was also stained for CSE (middle panels, brown color). Importantly, we identified myofibroblasts in complicated lesions expressing high CSE level (Figure 3). SMA-positive myofibroblasts (violet) coexpressing CSE (brown color) in their cytoplasm were abundant.

To further support this observation, we compared CSE expression in the aorta of $\mathrm{ApoE}^{-/-}$mice fed with normal or atherogenic diet for 8 weeks. Mice fed on the atherogenic diet provoked extensive atherosclerotic plaque formation which was associated with elevated expression of CSE as demonstrated by Western blot (Figure 1(b), lower panels). CSE was localized in endothelium, macrophages, and foam cells as revealed by immunohistochemistry (Figure 1(b), upper panel). For improved visibility, we show the same histological pictures with higher magnification as Supplementary Figure 2.
Furthermore, we investigated the endogenous sulfide levels in different types of the carotid arteries and found increased sulfide levels in atheroma compared to healthy vessel and complicated lesion (Figure 1(c)).

3.2. Sulfide Inhibited Lipid Peroxidation In Vitro and In Vivo. In accordance with previous findings [17], we observed that administration of $\mathrm{NaSH}$ solution reduced, whereas inhibition of CSE activity by DL-propargylglycine (PPG) increased atherogenic diet-induced atherosclerotic plaque formation in ApoE $^{-/-}$mice (Figure 4(a), left and right panels). Therefore, we examined the extent of oxidative injury by performing immunofluorescence staining for the cytotoxic lipid peroxidation product 4-hydroxynonenal (4-HNE) in aortic root in a vehicle or $\mathrm{NaSH}$-treated $\mathrm{ApoE}^{-/-}$mice. Strong positive 4-HNE immunostaining was observed in aorta from vehicle-treated mice, whereas 4 -HNE level was markedly lower in aorta from $\mathrm{NaSH}$-treated mice (Figure 4(b), left panel). To further confirm that lipid peroxidation was inhibited by sulfide, we measured thiobarbituric acid reactive substance (TBARS) content of the aorta derived from a vehicle or $\mathrm{NaSH}$-treated ApoE ${ }^{-/-}$mice. TBARS content of sulfidetreated aorta was approximately one-third of the vehicletreated control samples (Figure 4(b), right panel). Since heme oxygenase-1 (CSE) was shown to be induced by lipid hydroperoxide [25], we also tested whether sulfide alters HO-1 expression in an atherosclerotic mouse model. HO-1 was strongly upregulated in the aorta of $\mathrm{ApoE}^{-/-}$mice fed with atherogenic diet and it was mainly expressed by endothelial cell and macrophages (Figure 4(c)). We found that HO-1 mRNA level was reduced in NaSH-treated mice, presumably due to the attenuated oxidative stress (Figure 4(d)). Next, we examined whether sulfide releasing molecules could prevent lipid peroxidation of lipids derived from human atheromatous lesions in vitro. We provoked lipid peroxidation in vitro with heme or hemoglobin $(\mathrm{Hb})$ to model intraplaque hemorrhage. Heme induced a robust increase in lipid peroxides (LOOH) and TBARS content of plaque lipids which was inhibited by all sulfide donors (Suppl. Figures 3A and 3B). Similarly, sulfide-releasing molecules attenuated $\mathrm{Hb}$-mediated formation of both LOOH and TBARS (Suppl. Figures 3C and 3D). We also checked whether polysulfides and decomposed sulfide donors alter lipid peroxidation in vitro. Neither polysulfide nor decomposed sulfide donors were able to block lipid peroxidation (Suppl. Figure 5).

\subsection{Sulfide Inhibited the Formation of Lipid-Peroxidation} Products in Human Hemorrhaged Lesions. Next, we examined whether the different $\mathrm{H}_{2} \mathrm{~S}$-releasing compounds could prevent hemorrhage-mediated lipid-peroxidation upon intraplaque hemorrhage. Human carotid endarterectomy specimens with obvious macroscopic evidence of intraplaque hemorrhage (Suppl. Figure 4A) were homogenized and incubated at $37^{\circ} \mathrm{C}$ in the presence or absence of the sulfide donors $(200 \mu \mathrm{mol} / \mathrm{L})$. We determined LOOH and TBARS content of the samples at day 0 and day 4. During the four-day incubation, LOOH content increased about 2.7-fold, whereas the level of TBARS elevated by 2.4-fold (Suppl. Figures $4 \mathrm{~B}$ and $4 \mathrm{C}$ ). The formation of both $\mathrm{LOOH}$ and 

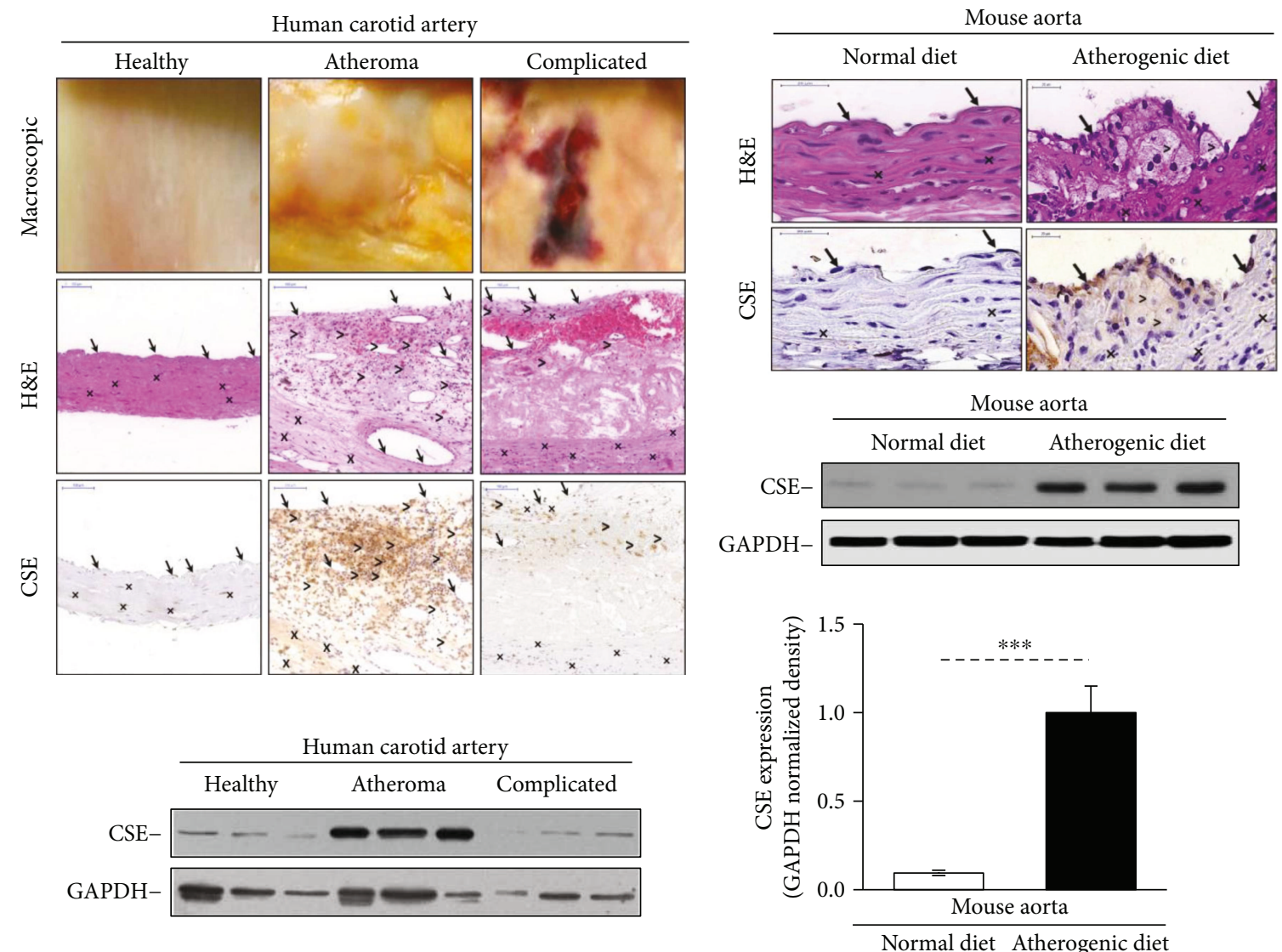

(b)

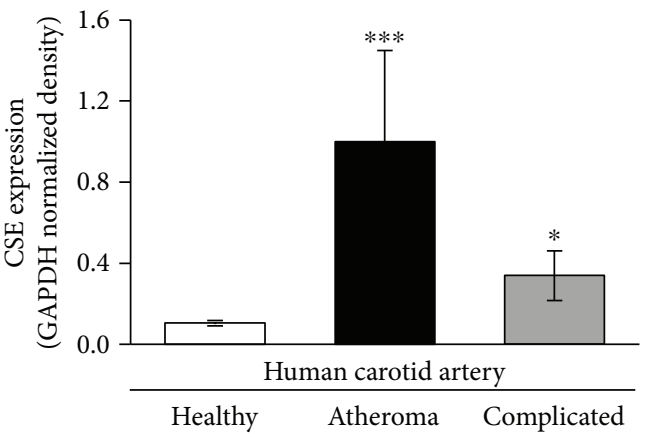

(a)

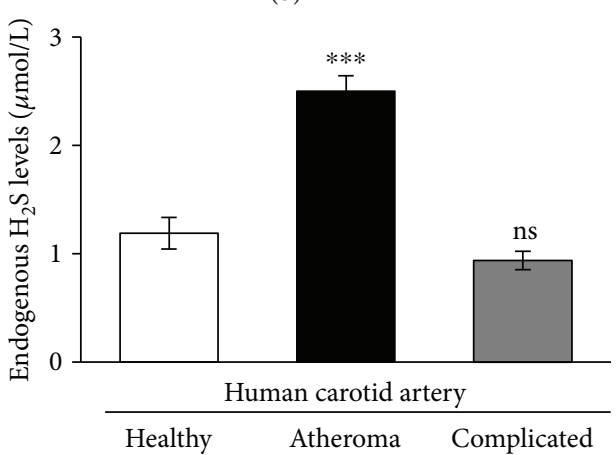

(c)

FIGURE 1: CSE is markedly upregulated in atheromatous lesions. (a, upper panels) Immunohistochemistry detection of the CSE expression in human carotid artery specimens. Macroscopic pictures, H\&E, and CSE staining are shown. Magnification of the human histology samples was 150x. Arrows indicate endothelial cells, crosses show smooth muscle cells, and comparison signs mark macrophages. (a, lower panels) Pieces of carotid artery representing the healthy vessel; atheromatous and complicated lesions were selected by macroscopic examination. Representative Western blot showing CSE expression in carotid artery tissue lysates $(20 \mu \mathrm{g} / \mathrm{lane})(N=3$, three human carotid artery specimens from three patients in each group). Immunoblots were reprobed with GAPDH. The bar graph shows CSE expression normalized to GAPDH. ${ }^{* * *} p<0.005$ and ${ }^{*} p<0.05$ compared to healthy samples. (b) ApoE ${ }^{-/-}$mice were kept on normal chow diet or atherogenic diet for 8 weeks. (b, upper panels) H\&E and CSE staining are shown. Magnification of the mice aortas was 700x. Arrows indicate endothelial cells, crosses show smooth muscle cells, and comparison signs mark macrophages. (b, lower panels) Representative Western blot showing CSE expressions of carotid artery samples $(10 \mu \mathrm{g} / \mathrm{lane})(n=3$, each performed in triplicate). Immunoblots were reprobed with GAPDH. The bar graph shows CSE expression normalized to GAPDH. (c) Endogenous $\mathrm{H}_{2} \mathrm{~S}$ levels in different types of the carotid arteries $(N=6)$.

TBARS were attenuated by the sulfide donors (Suppl. Figures 4B and 4C). Moreover, AP67 and AP72 were able to decrease $\mathrm{LOOH}$ content below the basal $\mathrm{LOOH}$ level measured at day 0 (Suppl. Figure 4B).
3.4. Sulfide Donor Molecules Inhibit Oxidative Cross-Linking of $\mathrm{Hb}$ Subunits. Covalent cross-linking of $\mathrm{Hb}$ occurs in advanced atherosclerotic lesions. To model the oxidative environment present in the atherosclerotic plaque in vitro, 


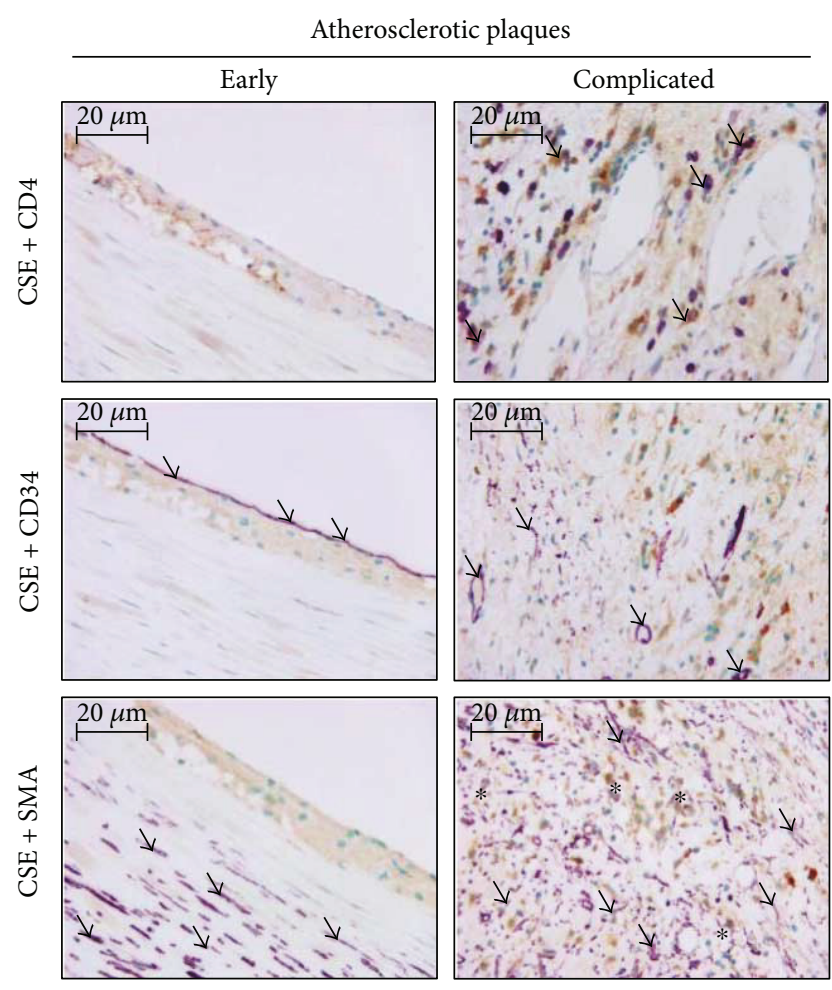

FIGURE 2: Double immunohistochemistry is demonstrating CSE expression in different cellular compartments of early (left) and complicated (right) atherosclerotic plaques of the carotid artery. Upper panels: CSE (DAB, brown color) and CD4 (VIP, violet) highlighting tissue macrophages (arrows); middle panels: CSE (DAB, brown color) and CD34 (VIP, violet) presenting endothelial cells (arrows); and lower panels: CSE (DAB, brown color) and smooth-muscle actin (VIP, violet) referring to smooth-muscle cells (arrows) and myofibroblasts (asterisk) ( $\times 400$ magnification).

we used $\mathrm{H}_{2} \mathrm{O}_{2}(25 \mu \mathrm{mol} / \mathrm{L})$ or oxLDL $(50 \mu \mathrm{g} / \mathrm{mL})$ to trigger such oxidative cross-linking of $\mathrm{Hb}(5 \mu \mathrm{mol} / \mathrm{L})$ in the presence or absence of sulfide donors. Covalently cross-linked Hb species were subsequently detected by Western blot analysis. The formations of dimeric, tetrameric, and multimeric $\mathrm{Hb}$ species were detected in both $\mathrm{H}_{2} \mathrm{O}_{2}$ and oxLDLtreated $\mathrm{Hb}$ samples. At a concentration of $200 \mu \mathrm{mol} / \mathrm{L}$, all the sulfide-generating molecules significantly inhibited the formation of covalently cross-linked $\mathrm{Hb}$ multimers triggered by either $\mathrm{H}_{2} \mathrm{O}_{2}$ or oxLDL (Figures 5(a)-5(d)). AP67 and AP72 provided complete inhibition against $\mathrm{H}_{2} \mathrm{O}_{2}$-induced $\mathrm{Hb}$ oxidation, and these donors were also the most effective at inhibiting oxLDL-mediated $\mathrm{Hb}$ oxidation (Figures 5(a)-5(d)).

3.5. Reactions of FerrylHb with Sulfide. To test the possibility that the observed protective effects of sulfide donors were due to the reduction of ferryl $\mathrm{Hb}$, we next investigated the kinetics of the reaction of ferrylHb species with sulfide in a cellfree system using stopped-flow spectrophotometry. Initially, ferrylHb was prepared in situ by the reaction of metHb with 5 molar equivalents of $\mathrm{H}_{2} \mathrm{O}_{2}$ in the first mixing cycle of a sequential stopped-flow experiment. Under our experimental conditions, the formation of ferrylHb was complete in $400 \mathrm{~s}$ and resulted in spectral transitions (see the 350-500 and 500-650 nm ranges on Figure 5(a), left and right panels) that were characteristic to the formation of ferrylHb. Therefore, sulfide was reacted with ferrylHb in the second mixing cycle using a delay time of $400 \mathrm{~s}$. Rapid changes in the UV-vis spectra predicted a favorable reaction between sulfide and ferrylHb under these conditions. The appearance of a new peak at $620 \mathrm{~nm}$ together with the shift of the Soret band at $400 \mathrm{~nm}$ and the absorbance increases at 530 and $580 \mathrm{~nm}$ were indicative of the formation of sulfhemoglobin (Figure 6(a), left and right panels). Kinetic traces were measured at a $>10$-fold excess of sulfide over ferrylHb to maintain pseudo-first-order conditions and recorded initially at 406, 425, and $570 \mathrm{~nm}$ (Figure 6(b), left and right panels). Under these conditions, they exhibited a biexponential character, which most likely corresponded to separated reactions of the alpha and beta chain ferryl heme centers (faster and slower phase, resp.) as shown before. The obtained pseudo-first-order rate constants from the double exponential fits of the kinetic traces at 406, 425, and $570 \mathrm{~nm}$ show similar linear correlations with the applied sulfide concentrations, indicating first-order dependencies of the rate law on both ferrylHb and sulfide concentrations (Figure 6(b), right panel). Therefore, the apparent second-order rate constants at $\mathrm{pH} 7.4$ were calculated from the slopes of the lines on Figure 6(b), right panel, to be $(1.43 \pm 0.06) \times 10^{3} \mathrm{M}^{-1} \cdot \mathrm{s}^{-1}$ and $(6.5 \pm 0.2) \times 10^{2} \mathrm{M}^{-1} \cdot \mathrm{s}^{-1}$ for the alpha and beta chains, respectively. The previous report proposed that related ferrylHb species are generated in the reactions of oxyHb with $\mathrm{H}_{2} \mathrm{O}_{2}$ as with metHb [26]. Indeed, we observed similar kinetics with sulfide for the ferrylHb species that were produced in the reaction of oxyHb with $\mathrm{H}_{2} \mathrm{O}_{2}$ as the ones described above for metHb (data not shown).

However, kinetic traces that were recorded at $620 \mathrm{~nm}$ (representing the formation of sulfheme $\mathrm{Hb}$ ) (Figure 6(c), left panel) indicated two orders of magnitude faster rates (also exhibiting double-exponential behaviors with secondorder rate constants of $(1.7 \pm 0.1) \times 10^{5}$ and $(6.5 \pm 0.3) \times$ $10^{4} \mathrm{M}^{-1} \cdot \mathrm{s}^{-1}$ ) (Figure $6(\mathrm{c})$, right panel). We obtained preliminary kinetic evidence that the relatively slow reactions recorded at $425 \mathrm{~nm}$ and the 2 orders of magnitude faster reactions at $620 \mathrm{~nm}$ were parallel and not consecutive reactions. As mentioned above, ferrylHb represents a mixture of oxidized $\mathrm{Hb}$ species, where an unpaired electron is located at different sites of the protein [27]. Therefore, we propose that the observed kinetically isolated reactions were due to different ferrylHb species reacting with sulfide. We are currently investigating the chemical nature of these ferrylHb species, but their characterization is outside the scope of the present study.

3.6. Hb-Lipid Interactions and Subsequent Endothelial Responses Are Attenuated by Sulfide. Interactions between $\mathrm{Hb}$ and lipids upon intraplaque hemorrhage result in the formation of reactive lipid mediators as well as oxidized $\mathrm{Hb}$ species. These molecules trigger oxidative stress and cell activation, respectively. To investigate whether sulfide could attenuate these harmful reactions, we treated oxidized LDL 
Complicated sclerotic plaque

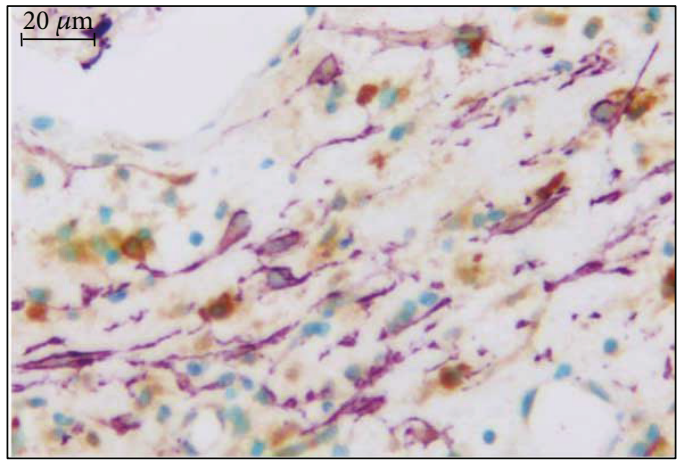

(a)
Myofibroblast

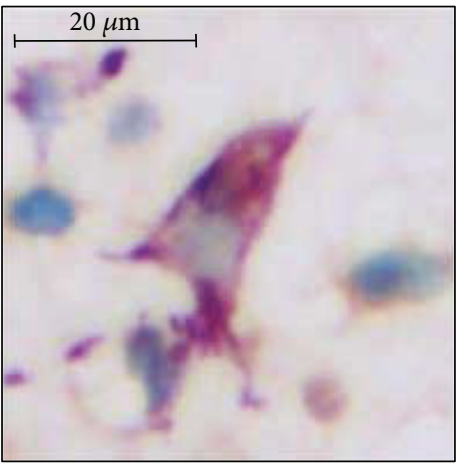

(b)

FIGURE 3: CSE expression in activated myofibroblasts in a cellular area of a complicated sclerotic plaque. (a) SMA+ myofibroblasts (VIP, violet) partially coexpress CSE (DAB, brown staining) in their cytoplasm. Additional CSE labeling can be observed in tissue macrophages (brown only) ( $\times 400$ magnification). (b) A single enlarged SMA+ fibroblast-type cell with cytoplasmic brown CSE-related colabeling ( $\times 1000$ magnification).

with sulfide donors for 4 hours. Then, HAoECs were exposed to the LDL samples for 6 hours. Oxidized LDL decreased cell viability by about $97 \%$ (Figure $7(\mathrm{a})$ ). Pretreatment of oxLDL with sulfide donors at the concentration of $200 \mu \mathrm{mol} / \mathrm{L}$ significantly attenuated oxLDL induced to HAoECs (Figure 7(a)). AP67 and AP72 were more potent at inhibiting LDL-induced cytotoxicity presumably because they generate $\mathrm{H}_{2} \mathrm{~S}$ more efficiently than GYY4137 [19] (Figure 7(a)). Sublethal concentrations of oxLDL induced the expression of heme oxygenase-1 (HO-1), a stress-responsive protein in HAoECs (Figure 7(b)). We found that HO-1 expression provoked by a sublethal dose of oxLDL was suppressed by AP67 and AP72 but not by NaSH and GYY4137 in HAoECs (Figure 7(b)). We also tested the constitutive heme oxygenase-2 (HO-2) expression in these samples and we found that HO-2 level remained unchanged (Figure $7(\mathrm{~b})$ ). $\mathrm{H}_{2} \mathrm{~S}$ donors at concentrations we used did not enhance the level of HO-1 and HO-2 in HAoECs (data not shown). Thus, in our system, heme oxygenases were not involved in the cellular responses provided by $\mathrm{H}_{2} \mathrm{~S}$. Oxidized $\mathrm{Hb}$ species in particular ferrylHb trigger endothelial cell activation, characterized by elevated expression of adhesion molecules and increased intercellular permeability. Therefore, we next examined whether sulfide donor molecules could modulate endothelial responses via inhibiting ferrylHb formation. $\mathrm{Hb}$ was treated with $\mathrm{H}_{2} \mathrm{O}_{2}$ in the absence or presence of the sulfide releasing molecules. Confluent HAoECs were then treated with the obtained samples, and VCAM-1 expression as a marker of endothelial cell activation, endothelial monolayer resistance, and intercellular gap formation was investigated.

We found that $\mathrm{Hb}$ samples treated with $\mathrm{H}_{2} \mathrm{O}_{2}$ in the presence of slow sulfide-releasing molecules were able to attenuate VCAM-1 expression, while $\mathrm{NaSH}$ could not diminish it (Figure 7(c)). Then, we investigated the integrity of HAoECs monolayers. Native $\mathrm{Hb}$ did not change HAoECs monolayer resistance compared to control cells during the 3-hour treatment (Figure 7(d), lower panel), but when HAoECs monolayers were exposed to oxidized $\mathrm{Hb}$, monolayer resistance was significantly decreased (Figure $7(\mathrm{~d})$, lower panel), suggesting that oxidized $\mathrm{Hb}$ provoked intercellular gap formation in accordance with previous observations [11, 15]. Importantly, each sulfide-releasing molecule attenuated the decline of monolayer resistance (Figure $7(\mathrm{~d})$, lower panel) presumably via the inhibition of ferrylHb formation. Moreover, AP67 and AP72 not only inhibited the oxHbmediated decrease in monolayer resistance but also increased resistance significantly above the nontreated HAoECs monolayer's resistance (Figure 7(d), lower panel). To confirm that the observed decrease in monolayer resistance upon treatment of HAoECs with oxidized $\mathrm{Hb}$ was due to intercellular gap formation, we performed immunostaining on cells after oxidized $\mathrm{Hb}$ exposure (Figure 7(d), upper panel). Accordingly, in the present studies, endothelium exposed to oxHb exhibited gaps between the cells visualized by F-actin staining (Figure $7(\mathrm{~d})$, upper panel). As demonstrated in panel E, rearrangement of F-actin cytoskeleton and subsequently the formation of intercellular gaps were prevented by NaSH, GYY4137, and AP67. We also tested if polysulfides and decomposed sulfide donors could affect endothelial responses. Interestingly, we found that polysulfides, but not decomposed sulfide donors, were able to inhibit oxLDL-induced cell death (Suppl. Figures 6A and 6B). Furthermore, increased expression of $\mathrm{HO}-1$ and VCAM-1 provoked by oxLDL or oxHb at a sublethal dose was not altered by polysulfides and decomposed sulfide donors (Suppl. Figures 6C and 6D).

3.7. Atherogenic Lipids and Proinflammatory Cytokines Increased the Expression of CSE in Diverse Cells of the Atherosclerotic Vessel Wall. To identify triggers and cell types responsible for altered CSE expression in the atherosclerotic vessel wall, we next exposed HASMCs, macrophages, and HAoECs to different agonists considered relevant in atherogenesis. First, we examined the effect of lipids, for example, LDL and plaque lipids extracted from human aorta specimens with lipid-rich atheromatous plaques. We challenged the cells with native and oxidized forms of these lipids and 


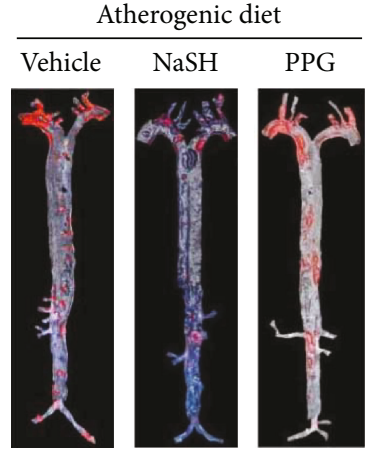

Hoechst
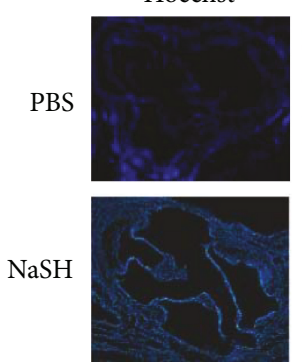

F-actin
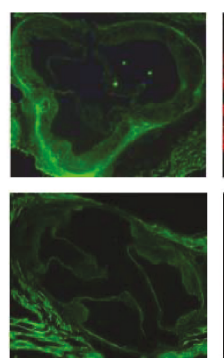

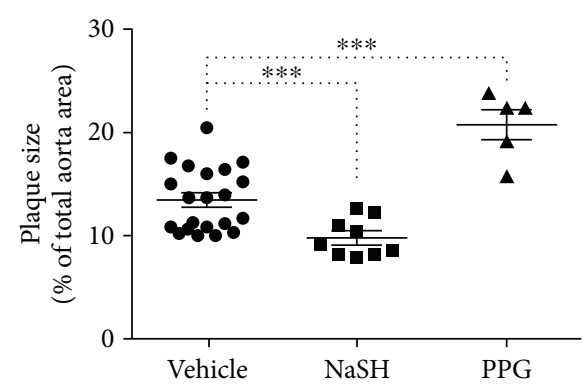

(a) 4-HNE

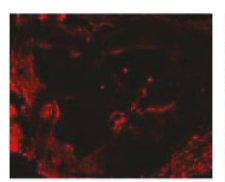

Overlay
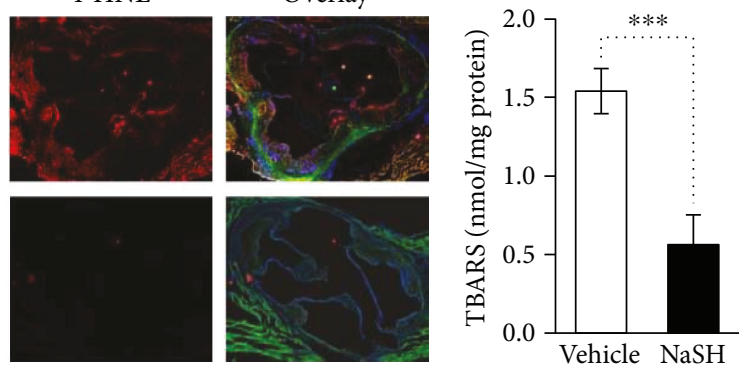

(b)

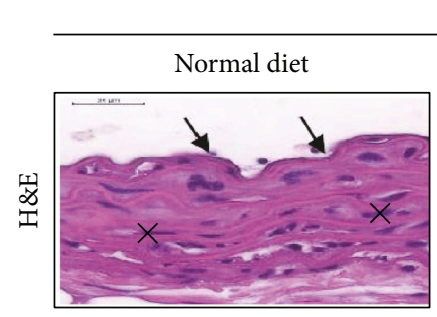

Mouse aorta
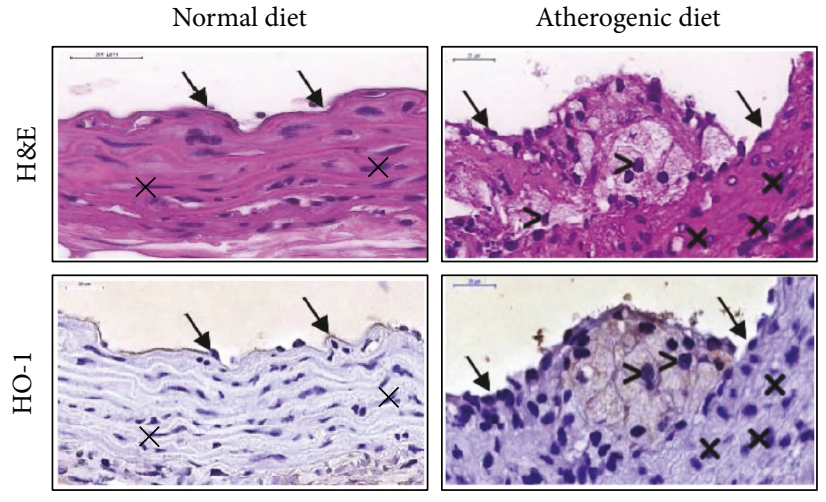

Atherogenic diet $+\mathrm{NaSH}$
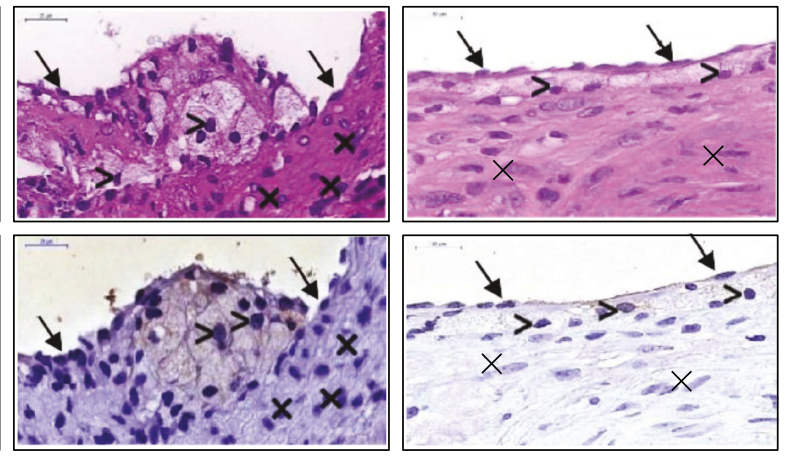

(c)

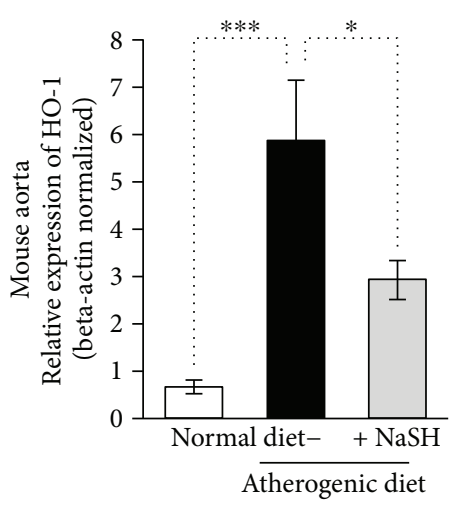

(d)

FIGURE 4: Sulfide inhibits lipid-peroxidation in vivo and in vitro. (a, left panel) Representative oil red O staining of aorta derived from ApoE ${ }^{-/-}$ mice fed with atherogenic diet and treated with $\mathrm{NaSH}(N=9)$, PPG $(N=5)$, or vehicle (PBS, $N=21)$ for 8 weeks. (a, right panel) Quantification of atherosclerotic plaque size was performed with ImageJ software. (b, left panel) Representative aortic sections $(6 \mu \mathrm{m})$ stained for F-actin (phalloidin-FITC, green), 4-HNE (red), and DNA (Hoechst, blue) $(N=9)$. (b, right panel) TBARS content of aorta derived from $\mathrm{ApoE}^{-1-}$ mice fed with atherogenic diet and treated with vehicle $(N=9)$ or $\mathrm{NaSH}$ for 8 weeks $(N=9)$. (c) ApoE ${ }^{-1-}$ mice were fed with regular diet $(N=9)$ or atherogenic diet for 8 weeks. Parallel with the atherogenic diet, the mice were kept intraperitoneally vehicle $(N=9)$ or $\mathrm{NaSH}(N=9)$. Immunohistology was showing hematoxylin and eosin and HO-1 staining of mice aorta samples. Endothelial cells are indicated by arrows, smooth muscle cells were marked by cross, and macrophages were marked by comparison signs. The magnification of the mice aortas was 700x. (d) Real-time qPCR was showing HO-1 relative expression in mouse aorta. * indicates statistical significance $(p<0.05)$. $* * *$ indicates statistical significance $(p<0.0001)$.

applied $\mathrm{H}_{2} \mathrm{O}_{2}$ as a positive control (Figure 8(a)). We found that all the three cell types expressed CSE and that $\mathrm{H}_{2} \mathrm{O}_{2}$ exposure upregulated the expression of this $\mathrm{H}_{2} \mathrm{~S}$ synthesizing enzyme in HASMCs and macrophages. Both HASMCs and macrophages responded to oxLDL, native, and oxidized plaque lipids by upregulating the expression of CSE (Figure 8(a), left and middle panels). Next, we challenged the cells with different forms of $\mathrm{Hb}$ and $\mathrm{Hb}$ breakdown products such as heme and iron which are known to accumulate in the atherosclerotic lesions upon intraplaque hemorrhage [10]. When exposed to $\mathrm{Hb}$, oxidized $\mathrm{Hb}$, or heme, HASMCs and macrophages upregulated the expression of CSE, whereas iron 


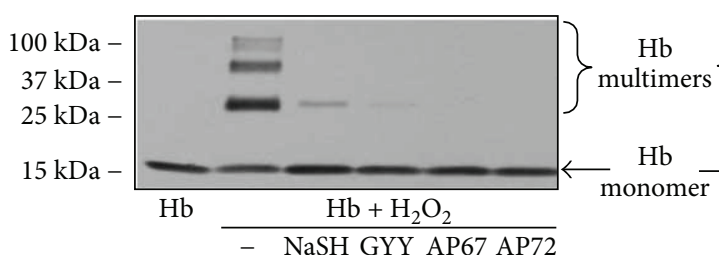

(a)

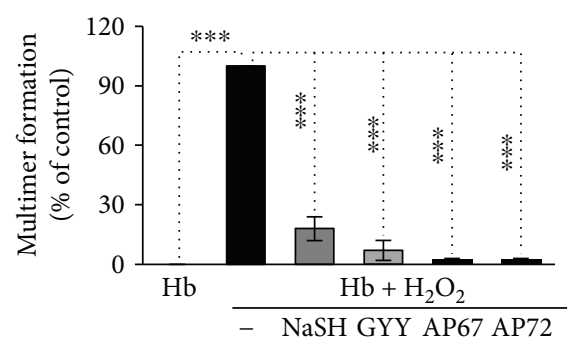

(b)

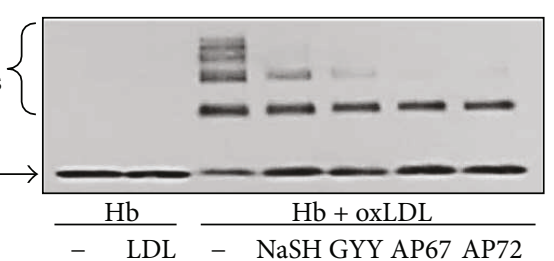

(c)

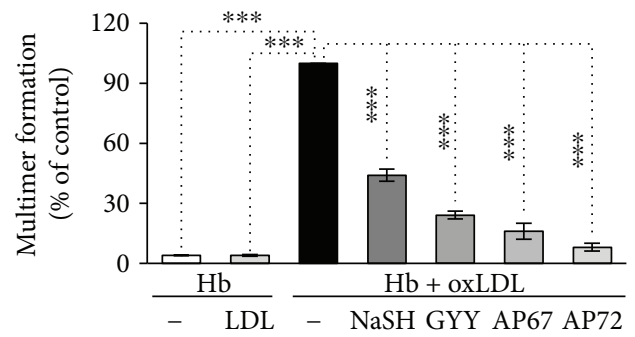

(d)

Figure 5: Sulfide inhibits the formation of covalently cross-linked $\mathrm{Hb}$ multimers. (a) $\mathrm{Hb}(5 \mu \mathrm{mol} / \mathrm{L})$ was incubated with $\mathrm{H}_{2} \mathrm{O}_{2}(75 \mu$ mol/L) in the presence or absence of the $\mathrm{H}_{2} \mathrm{~S}$ donors NaSH, GYY4137, AP67, and AP72 (200 $\left.\mu \mathrm{mol} / \mathrm{L}\right)$ at $37^{\circ} \mathrm{C}$ for 90 minutes. Samples $(0.5 \mu \mathrm{g} \mathrm{Hb})$ were subjected to SDS-PAGE and Hb species were detected by Western blotting. Representative experiment, $n=3$. (b and d) Quantification of the multimer formation was showed. (c) $\mathrm{Hb}(5 \mu \mathrm{mol} / \mathrm{L})$ was incubated with oxLDL $(50 \mu \mathrm{g} / \mathrm{ml})$ in the presence or absence of the sulfide donors $\mathrm{NaSH}, \mathrm{GYY} 4137, \mathrm{AP} 67$, and AP72 $(200 \mu \mathrm{mol} / \mathrm{L})$ at $37^{\circ} \mathrm{C}$ for 4 hours. Samples $(0.5 \mu \mathrm{g} \mathrm{Hb})$ were subjected to SDS-PAGE and Hb species were detected by Western blotting. Representative experiment, $n=3$. *** indicates statistical significance $(p<0.0001)$.

treatment caused a marked decrease of CSE expression in HASMCs, but did not modulate CSE expression in macrophages (Figure 8(b), left and middle panels). We also examined the upregulation of CSE by various forms of hemoglobin, lipids, and proinflammatory cytokines in HAoECs. CSE expression was not altered in HAoECs exposed to oxHb, oxLDL, and oxidized lipids derived from atheromatous plaque (Figures 8(a) and 8(b), right panels). To examine the effect of proinflammatory mediators, we next exposed the cells to IL- $1 \beta$ and TNF- $\alpha$. Figures 8 (c) shows that CSE expression was induced in HASMCs and macrophages after cytokine stimulation. On the contrary, CSE level was significantly increased in cells treated with TNF- $\alpha$ as it was observed in HAoECs (Figure 8(c), right panels).

\section{Discussion}

The oxidative environment in the atherosclerotic lesion triggers lysis of invading erythrocytes and the subsequent release of $\mathrm{Hb}$ upon intraplaque hemorrhage [10]. A complex interplay exists between atheroma lipids and cellfree $\mathrm{Hb}$ that leads to further lipid-peroxidation and $\mathrm{Hb}$ oxidation $[10-12,22]$.

In the reactions between $\mathrm{Hb}$ and plaque lipids, different oxidized $\mathrm{Hb}$ derivatives are formed (metHb $\left(\mathrm{Fe}^{3+}\right)$, ferrylHb $\left(\mathrm{Fe}^{4+}=\mathrm{O}^{2-}\right)$ ) [10-12], resulting in the covalently crosslinked species. In our current study, we demonstrated that sulfide inhibited oxidative cross-linking of $\mathrm{Hb}$ subunits, the hallmark of the ferrylHb formation. These effects could be attributed to the ability of sulfide to reduce $\mathrm{LOOH}$ content of oxLDL because LOOH was identified previously as the most cytotoxic lipid-peroxidation product in oxLDL toward vascular endothelium [22]. However, as we argued previously, the antioxidant properties of sulfide in biological systems are most likely not due to direct scavenging of oxidant species, because protein thiols and GSH are present in much larger concentrations compared to sulfide. Hb crosslinking proceeds via ferrylHb intermediate species, those we found to be scavenged rapidly by sulfide, hence providing an alternative molecular model for sulfide-mediated inhibition of $\mathrm{Hb}$ oligomerization. The measured rate constants for the reactions of ferrylHb species with sulfide represent at least 1-3 orders of magnitude faster reactions (for the slower reactions recorded at $425 \mathrm{~nm}$ and the faster ones at $620 \mathrm{~nm}$, resp.) compared to those with ascorbate or urate [28] that are the previously proposed primary hemeredox-intermediate-scavenging antioxidants (because thiols in most cases have no access to the metal center at the active site). Also, the relatively high stability of the ferrylHb species implies that $\mathrm{Hb}$ oligomers must form in much slower reactions. Furthermore, the fact that $\mathrm{Hb}$ oligomerization was associated with intraplaque hemorrhage suggests a role for ferrylHb-initiated oxidative stress in the underlying molecular mechanisms of the pathophysiology of complicated atherosclerotic lesions [10]. Hence, the demonstration of sulfide-mediated reduction of ferrylHb species is a novel observation which could explain at least some of the observed cytoprotective effects of sulfide in our current model and adds to the rapidly growing body of literature detailing $\mathrm{H}_{2} \mathrm{~S}$-mediated cytoprotection.

Additionally, oxidized $\mathrm{Hb}$ species, in particular ferrylHb, induce proinflammatory signaling targeted to the vascular endothelium. By inhibiting $\mathrm{Hb}$ oxidation, sulfide donors also attenuated $\mathrm{Hb}$ oxidation-associated decrease in endothelial monolayer integrity and intercellular gap formation, as well as the induction of the adhesion molecule, VCAM-1.

Oxidized $\mathrm{Hb}$ species release heme, a potent trigger of lipid peroxidation $[14,25]$. In our current study, sulfide 

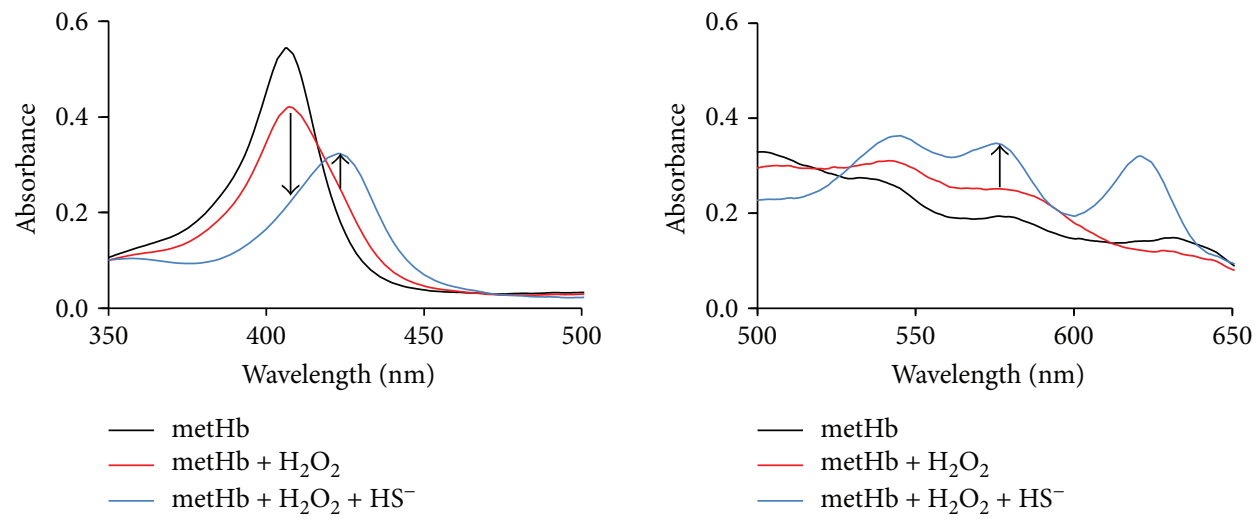

(a)
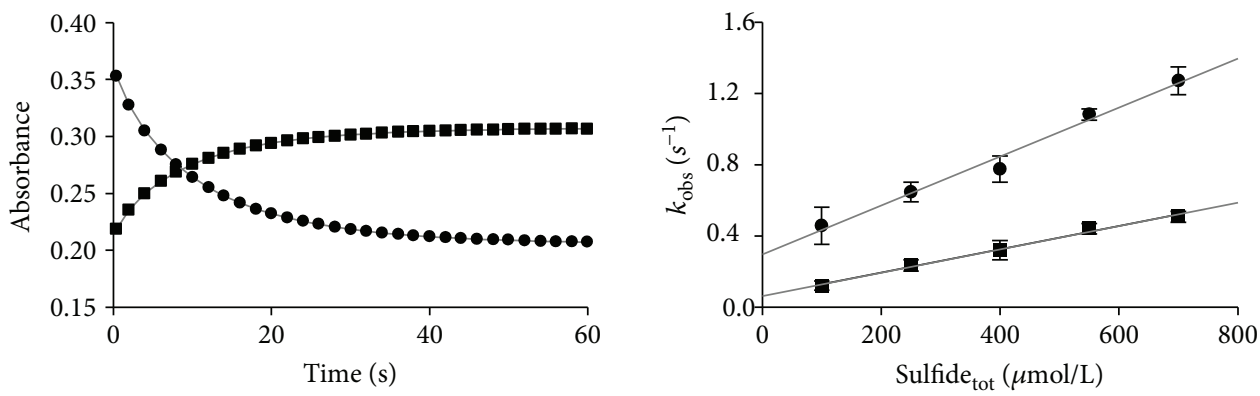

- $425 \mathrm{~nm}$

- $\alpha$-Chain

- $\beta$-Chain

(b)
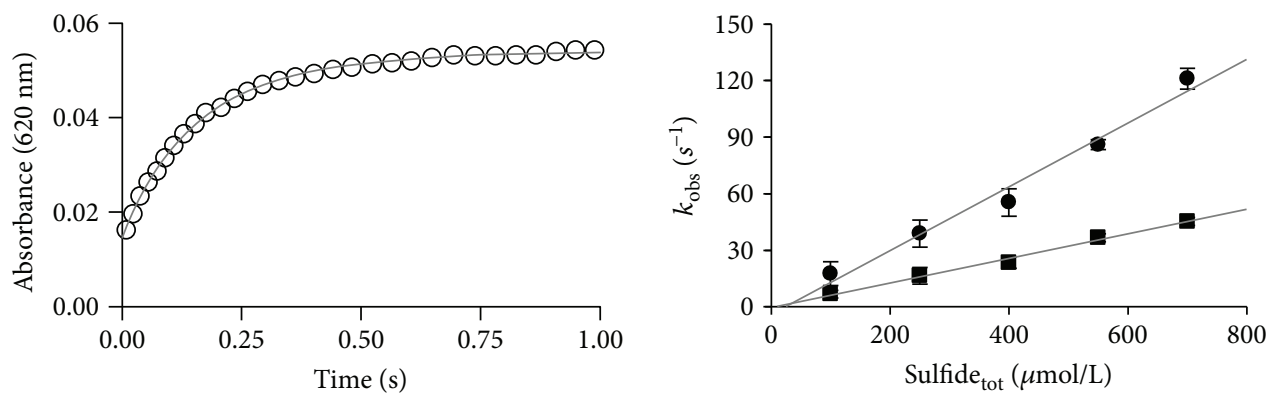

- $\alpha$-Chain

- $\beta$-Chain

(c)

Figure 6: Reactions of ferrylHb with sulfide. (a, left and right panels) Representative UV-vis spectra of $4 \mu$ mol/L metHb (black line), reaction of $4 \mu \mathrm{mol} / \mathrm{L}$ metHb with $8 \mu \mathrm{mol} / \mathrm{L} \mathrm{H}_{2} \mathrm{O}_{2}$ after $400 \mathrm{~s}$ (red line) and reaction of $4 \mu \mathrm{mol} / \mathrm{L}$ ferrylHb with $100 \mu \mathrm{mol} / \mathrm{L}$ sulfide after an additional $60 \mathrm{~s}$ (blue line). Arrows indicate wavelength values where the kinetic runs were recorded. (b, left panel) Representative stopped-flow kinetics traces for the reaction of $4 \mu \mathrm{mol} / \mathrm{L}$ ferrylHb with $100 \mu \mathrm{mol} / \mathrm{L}$ sulfide at $406 \mathrm{~nm}$ (circles) and $425 \mathrm{~nm}$ (squares) and the corresponding double exponential fits (solid lines). (b, right panel) Sulfide concentration dependencies of the obtained pseudo-first-order rate constants from the double exponential fits of the stopped-flow kinetic traces $(\lambda=425 \mathrm{~nm})$. MetHb $(4 \mu \mathrm{mol} / \mathrm{L})$ was reacted with $\mathrm{H}_{2} \mathrm{O}_{2}(8$ or $20 \mu \mathrm{mol} / \mathrm{L})$ in the presence of sulfide $(100-700 \mu \mathrm{mol} / \mathrm{L})$. The faster (circles) and slower (squares) reactions represent reactions of the ferryl moieties of the alpha and beta chains, respectively. Data points and error bars represent the average and standard deviations of 4 independent experiments. (c, left panel) Representative stopped-flow kinetics traces for the reaction of $4 \mu \mathrm{mol} / \mathrm{L}$ ferrylHb with $100 \mu \mathrm{mol} / \mathrm{L}$ sulfide at $620 \mathrm{~nm}$ (blank circles) and the corresponding double exponential fit (solid lines). (c, right panel) Sulfide concentration dependence of the pseudo-first-order rate constant for the reaction of ferrylHb with sulfide from the double exponential fits of the kinetic traces, where ferrylHb was generated in the reaction of $8 \mu \mathrm{mol} / \mathrm{L}$ metHb with $40 \mu \mathrm{mol} / \mathrm{L} \mathrm{H}_{2} \mathrm{O}_{2}$ in the first mixing cycle of a sequential stopped-flow experiment, followed by mixing with sulfide solutions in a $1: 1$ ratio in the second mixing cycle after a $240 \mathrm{~s}$ delay time. The faster (circles) and slower (squares) reactions represent the reactions of the ferryl moieties of the alpha and the beta chains, respectively. Data points and error bars represent the average and standard deviations of 3 independent experiments. 


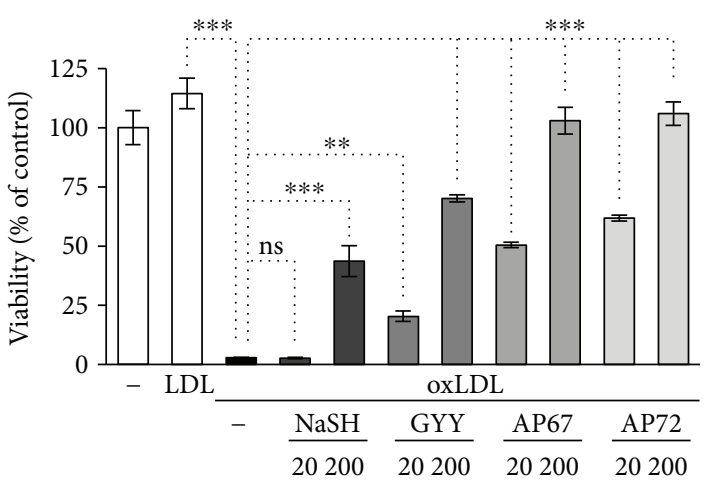

(a)

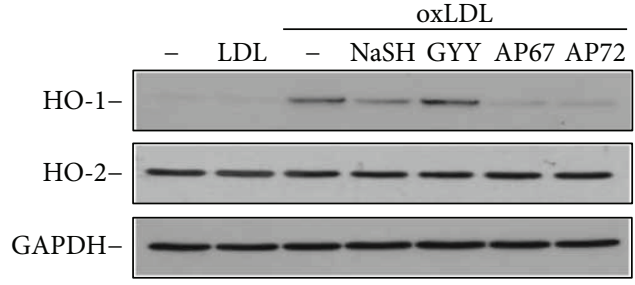

(b)

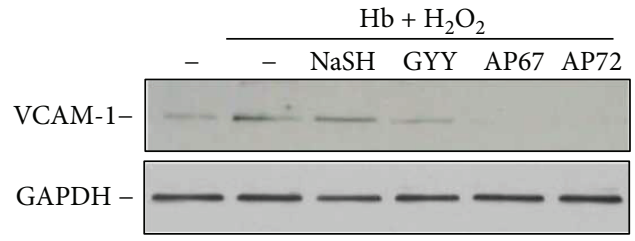

(c)
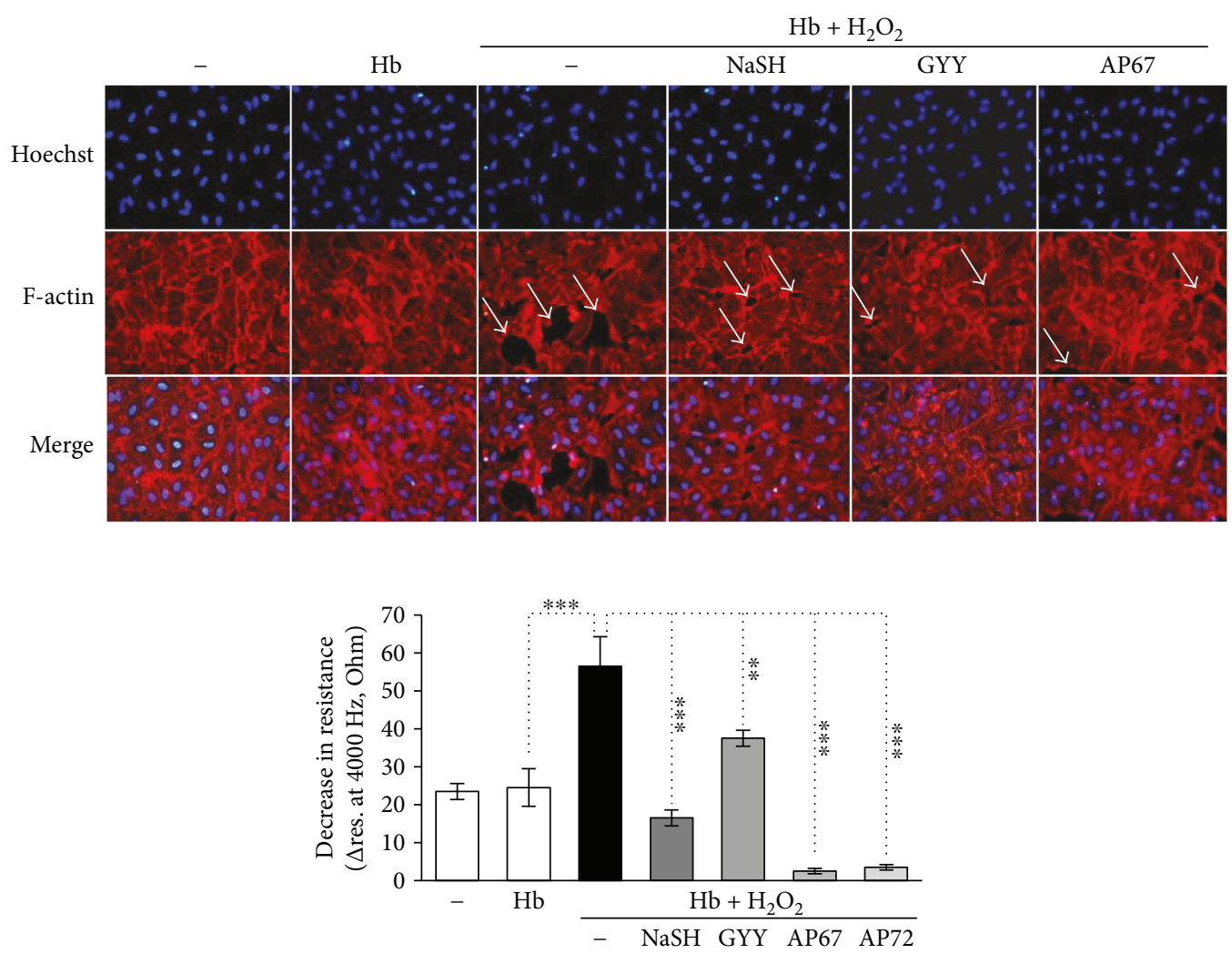

(d)

FIGURE 7: Endothelial responses provoked by Hb-lipid interactions are attenuated by sulfide donors. (a) OxLDL (200 $\mu \mathrm{g} / \mathrm{mL})$ was incubated with sulfide donors NaSH, GYY4137, AP67, and AP72 at the concentrations of 20 and $200 \mu \mathrm{mol} / \mathrm{L}$ at $37^{\circ} \mathrm{C}$ for 24 hours. Confluence HAoECs were exposed to the LDL samples for 4 hours then cell viability was determined by MTT assay. Representative experiment, $n=3$, each performed in 8 wells in parallel. (b) OxLDL $(200 \mu \mathrm{g} / \mathrm{mL})$ was incubated with sulfide donors NaSH, GYY4137, AP67, and AP72 at the concentration of 20 and $200 \mu \mathrm{mol} / \mathrm{L}$ at $37^{\circ} \mathrm{C}$ for 24 hours. Confluence HAoECs were exposed to LDL samples (50 $\left.\mu \mathrm{g} / \mathrm{mL}\right)$ for 8 hours. HO-1 and HO-2 protein expressions were determined by Western blotting. Representative experiment, $n=3$. (c-e) $\mathrm{Hb}(10 \mu \mathrm{mol} / \mathrm{L})$ was incubated with $\mathrm{H}_{2} \mathrm{O}_{2}(50 \mu \mathrm{mol} / \mathrm{L})$ in the presence or absence of sulfide donors $\mathrm{NaSH}, \mathrm{GYY} 4137, \mathrm{AP} 67$, and $\mathrm{AP} 72(200 \mu \mathrm{mol} / \mathrm{L})$ at $37^{\circ} \mathrm{C}$ for 90 minutes. (c) Confluence HAoECs were exposed to the obtained Hb samples for 8 hours and VCAM-1 expression was determined by Western blotting. Representative experiment, $n=3$. (d, lower panel) Confluence HAoECs cultured in ECIS plates were exposed to the obtained $\mathrm{Hb}$ samples and transendothelial electrical resistance was monitored by ECIS instrument for 3 hours. Representative experiment, $n=3$, each performed in triplicate (d, upper panel). HAoECs grown on coverslips, upon reaching confluence cells were exposed to the Hb samples for 8 hours. Cells were stained for F-actin (phalloidin-TRITC, red) and DNA (Hoechst, blue). White arrows show intercellular gaps. Representative image, $n=5$. $* *$ indicates statistical significance $(p<0.001)$. $* * *$ indicates statistical significance $(p<0.0001)$. 

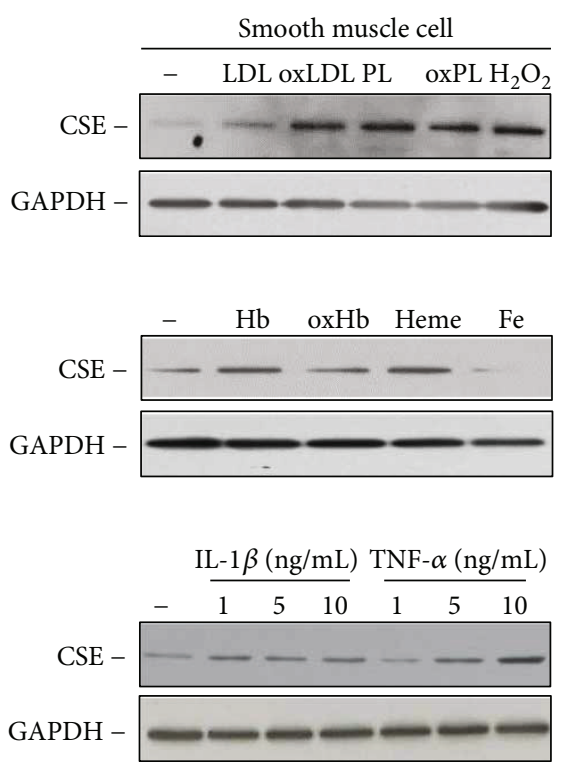

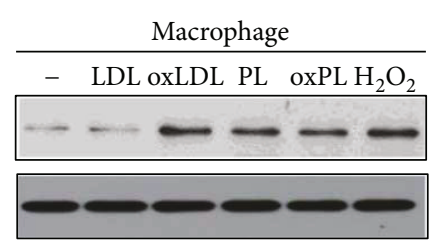

(a)

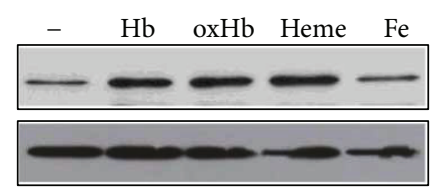

(b)

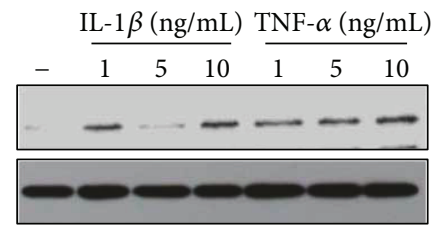

(c)
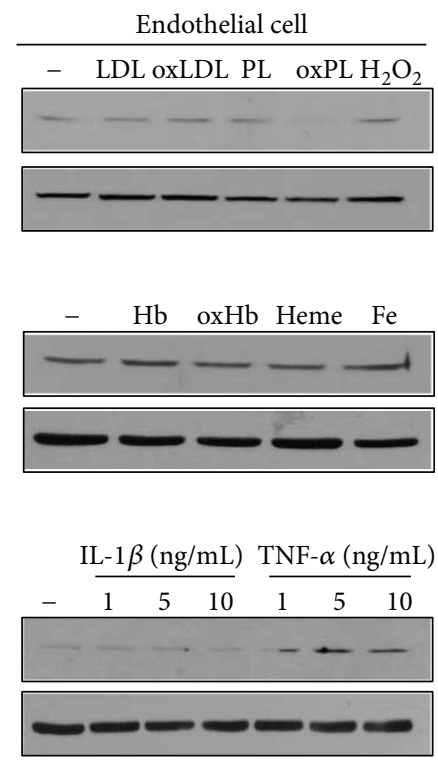

Figure 8: Modulators of CSE expression in HASMCs, macrophages, and endothelial cells. (a) Confluent HASMCs, RAW264.7 cells, and HAoECs were exposed to LDL $(50 \mu \mathrm{g} / \mathrm{mL})$, oxLDL $(50 \mu \mathrm{g} / \mathrm{mL}), \mathrm{PL}(500 \mu \mathrm{g} / \mathrm{mL})$, oxPL $(500 \mu \mathrm{g} / \mathrm{mL})$, and $\mathrm{H}_{2} \mathrm{O}_{2}(100 \mu \mathrm{mol} / \mathrm{L}) \mathrm{for}$ 8 hours. (b) Confluent HASMCs, RAW264.7 cells, and HAoECs were exposed to $\mathrm{Hb}$, oxHb, heme (50 $\mu$ mol/L heme group each), and Fe-ammonium citrate $(50 \mu \mathrm{mol} / \mathrm{L})$ for 8 hours. (c) Confluent HASMCs, RAW264.7 cells, and HAoECs were exposed to IL-1 $\beta$ (1-5-10 ng/mL) or TNF- $\alpha$ (1-5-10 ng/mL) for 8 hours. Representative Western blots showing CSE expressions of cell lysates $(20 \mu \mathrm{g} / \mathrm{lane})$ $(n=3)$. Immunoblots were reprobed with GAPDH.

donors inhibited $\mathrm{Hb}$ or heme-mediated oxidation of soft plaque lipids derived from human atheroma. We have also shown that sulfide-releasing molecules attenuated lipid peroxidation in complicated lesions exhibiting evidence of hemorrhage. Chemically, $\mathrm{H}_{2} \mathrm{~S}$ is a reductant, and the previous study revealed that it converts lipid hydroperoxides into lipid-alcohols in oxLDL in vitro [29]. Importantly, we found that sulfide reduced lipid hydroperoxide content of complicated lesions with hemorrhage.

Using human carotid artery specimens and mice aorta derived from an experimental atherosclerosis model, here, we demonstrated that the expression of CSE is markedly upregulated in vessels with atheromatous plaques and complicated lesions. Macrophages, activated myofibroblasts, and foam cells exhibited marked CSE expression in the lesions, and interestingly, the CSE-positive cells were more common in atheromatous plaques compared to complicated lesions. The atherosclerotic plaque is rich in reactive oxygen species, reactive lipid mediators, proinflammatory cytokines, and upon plaque hemorrhage, contains different hemoglobin oxidation products. Here, we showed that all the major cell types of the atherosclerotic vessel wall, that is, endothelial cells, vascular smooth muscle cells, and macrophages, expressed CSE in a stress-responsive manner. We identified proinflammatory cytokines (TNF- $\alpha$, IL-1 $\beta$ ), lipid mediators (oxLDL, plaque lipid), and hemoglobin oxidation products (ferrylHb) that could contribute the high expression of CSE in blood vessels obtained from human atheromatous plaques and complicated lesions.

As we investigated the effects of a CSE inhibitor (PPG) in atherosclerotic plaque formation in vivo, we found that PPG treatment increased plaque formation in the presence of an atherogenic diet confirming Wang et al.'s and Mani et al.'s previous findings $[17,18]$. This suggests that the $\mathrm{CSE} / \mathrm{H}_{2} \mathrm{~S}$ system inhibits the development of atheromatous lesions. Unfortunately, in $\mathrm{ApoE}^{-/-}$mice model, there is no evidence of the development of complicated lesions. To our knowledge, there is no animal model for studying the fate of complicated lesions. In human, the main pathogenic event in the progression of atherosclerosis is the formation of complicated lesions with obvious macroscopic evidence of intraplaque hemorrhage. We demonstrate that complicated lesions with obvious macroscopic evidence of intraplaque hemorrhage in humans exhibit less CSE expression compared to an atheromatous plaque. These data support the beneficial role of $\mathrm{CSE} / \mathrm{H}_{2} \mathrm{~S}$ in the progression of atherosclerosis and does not provide evidence for an association of CSE upregulation and atherosclerosis. It should be noted that there is no animal model available at the moment for verifying the function of $\mathrm{H}_{2} \mathrm{~S}$ for controlling the prooxidant and proinflammatory ferrylHb. Our aim is in the future to establish a model for the development and progression of complicated lesions. Prevention of plaque rupture and infiltration of red blood cells into the atheroma might provide a novel approach to inhibit the progression of lesions in human.

In conclusion, the present study provides evidence that high vascular expression of CSE defines atheromatous plaques and complicated lesions, both in human carotid atherosclerotic lesions and in an experimental hyperlipidemiainduced atherosclerotic mouse model. Based on our in vitro findings, we propose that the elevated CSE expression might 


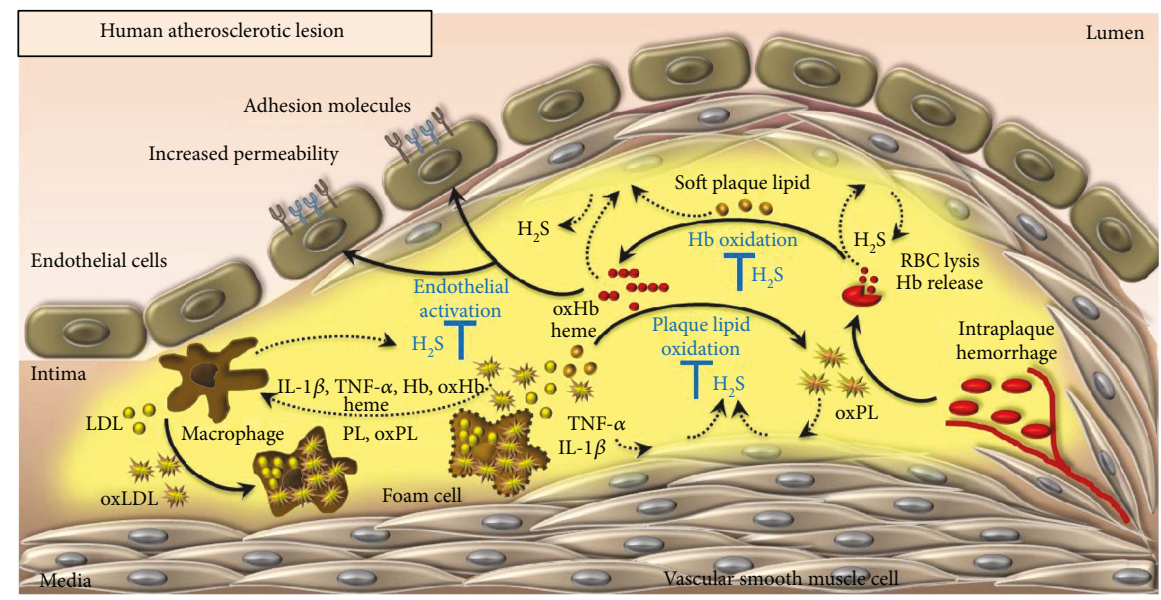

(a)

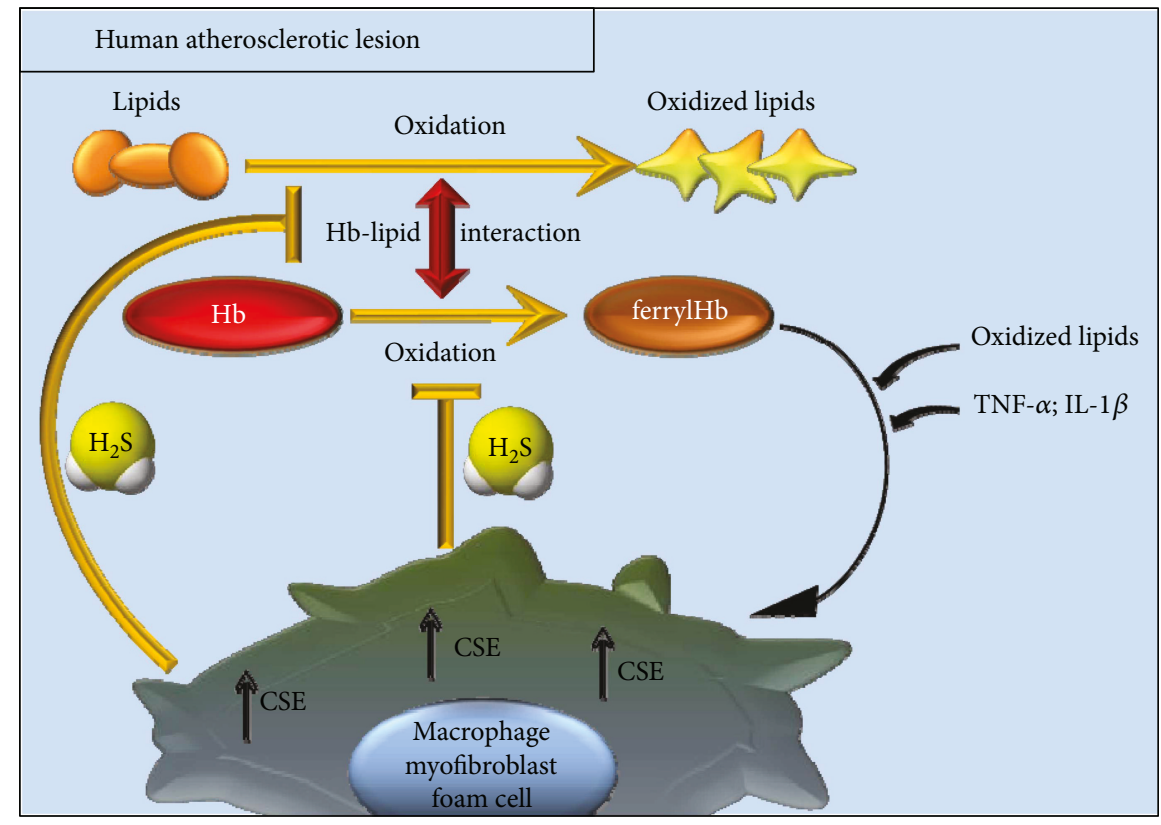

(b)

FIgURE 9: Proposed protective actions of $\mathrm{H}_{2} \mathrm{~S}$ in the atherosclerotic plaque. (a) Upon infiltration of RBCs into the atherosclerotic lesion erythrocytes are lysed and oxidation of liberated $\mathrm{Hb}$ occurs followed by heme release. Oxidized Hb forms and the released heme trigger further lipid peroxidation. FerrylHb exhibits proinflammatory property provoking endothelial cell activation characterized by intercellular gap formation and increased adhesion molecule expression. Endothelial activation facilitates monocyte adhesion and transendothelial migration. (b) In the reactions between $\mathrm{Hb}$ and plaque lipids, different oxidized $\mathrm{Hb}$ derivatives are formed including met $\mathrm{Hb}$ and ferrylHb species. Macrophages, foam cells, and smooth muscle cell-derived myofibroblasts respond to such an insult (ferrylHb, heme, plaque lipids, and the proinflammatory cytokines IL- $1 \beta$ and TNF- $\alpha$ ) by upregulating CSE expression. The increased production of $\mathrm{H}_{2} \mathrm{~S}$ inhibits (i) oxidation of $\mathrm{Hb}$ preventing the formation of ferryl $\mathrm{Hb}$ derivatives (a novel function as a heme-redox-intermediate-scavenging antioxidant), (ii) oxidation of plaque lipids, and subsequently (iii) activation of endothelium.

serve as a compensatory atheroprotective response, in which the produced $\mathrm{H}_{2} \mathrm{~S}$ prevents the formation of prooxidant and proinflammatory lipid mediators and $\mathrm{Hb}$ forms and subsequent endothelial responses provoked by these species (Figures 9(a) and 9(b)).

\section{Conflicts of Interest}

The authors declare that they have no conflicts of interest.

\section{Acknowledgments}

The research group is supported by the Hungarian Academy of Sciences (11003). This work was supported by Hungarian Government Grants (OTKA) K112333 (József Balla), K109843 (Péter Nagy), and K116024 (Viktória Jeney) and Marie Curie International Reintegration Grant PIRG08GA-2010-277006 (Péter Nagy). Péter Nagy is a János Bolyai Research Scholar of the Hungarian Academy of Sciences. Viktória Jeney was supported by Zoltán Magyary Fellowship 
(TÁMOP 4.2.4.A/2-11/1-2012-0001). László Potor was supported by János Apáczai-Csere Fellowship (TÁMOP 4.2.4.A/2-11/1-2012-0001). The project was cofinanced by the European Union and the European Social Fund (ESF) GINOP-2.3.2-15-2016-00043 IRONHEARTH and EFOP3.6.2-16-2017-00006 LIVE LONGER. Matthew Whiteman and Mark E. Wood have filed patent applications for AP67 and AP72 and related compounds. The authors thank Livia Beke for the technical assistance in performing the histology staining.

\section{Supplementary Materials}

Supplementary Figure 1: CSE is markedly upregulated in human atheromatous lesions immunohistochemistry detection of the CSE expression in human carotid artery specimens. H\&E and CSE staining are shown. Magnification of the human histology samples was 150x. Arrows indicate endothelial cells, crosses show smooth muscle cells, and comparison signs mark macrophages. Supplementary Figure 2: CSE is markedly upregulated in mouse atheromatous lesions. $\mathrm{ApoE}^{-1-}$ mice were kept on normal chow diet or atherogenic diet for 8 weeks. H\&E and CSE staining are shown. Magnification of the mice aortas was 700x. Arrows indicate endothelial cells, crosses show smooth muscle cells, and comparison signs mark macrophages. Supplementary Figure 3: sulfide donors were inhibited lipid peroxidation in vitro. (A-B) Soft plaque lipids $(400 \mu \mathrm{g} / \mathrm{mL})$ were incubated with heme $(5 \mu \mathrm{mol} / \mathrm{L})$ alone or in the presence of sulfide donors $\mathrm{NaSH}$, GYY4137, AP67, and AP72 $(200 \mu \mathrm{mol} / \mathrm{L})$ at $37^{\circ} \mathrm{C}$ for 24 hours, followed by determination of TBARS and LOOH. Representative experiment, $N=3$, each performed in triplicate. (C-D) Soft plaque lipids $(400 \mu \mathrm{g} / \mathrm{mL})$ were incubated with $\mathrm{Hb}(20 \mu \mathrm{mol} / \mathrm{L})$ alone or in the presence of sulfide donors NaSH, GYY4137, AP67, and AP72 $(200 \mu \mathrm{mol} / \mathrm{L})$ at $37^{\circ} \mathrm{C}$ for 48 hours, followed by determination of TBARS and $\mathrm{LOOH}$. Representative experiment, $n=3$, each performed in triplicate. Supplementary Figure 4: sulfide inhibits lipid-peroxidation in complicated lesions. (A) Macroscopic picture, $\mathrm{H} \& \mathrm{E}$ staining, and $\mathrm{Hb}$ staining of human complicated lesions are shown. (B-C) Human carotid artery specimens with obvious macroscopic evidence of intraplaque hemorrhage were homogenized. The homogenate $(5 \mathrm{mg} /$ $\mathrm{mL}$ ) was incubated in the presence or absence of the sulfide donors NaSH, GYY4137, AP67, and AP72 $(200 \mu \mathrm{mol} / \mathrm{L})$ at $37^{\circ} \mathrm{C}$ for 4 days. LOOH and TBARS levels were determined on day 0 and day 4. Representative experiment, $n=3$. Supplementary Figure 5: polysulfides and decomposed sulfide donors not able to block the lipid peroxidation. (A) LDL $(200 \mu \mathrm{g} / \mathrm{ml})$ was incubated with heme $(5 \mu \mathrm{mol} / \mathrm{L})$ and $\mathrm{H}_{2} \mathrm{O}_{2}$ in the presence or absence of $\mathrm{HSX}^{-}$or decomposed sulfide donors NaSH, GYY4137, AP67, and AP72 at the concentrations of 20 and $200 \mu \mathrm{mol} / \mathrm{L}$ at $37^{\circ} \mathrm{C}$ for 60 minutes followed by determination of TBARS and LOOH. Representative experiment, $n=3$, each performed in triplicate. (B) Soft plaque lipids $(400 \mu \mathrm{g} / \mathrm{mL})$ were incubated with heme $(5 \mu \mathrm{mol} / \mathrm{L})$ alone or in the presence of $\mathrm{HSX}^{-}$or decomposed sulfide donors NaSH, GYY4137, AP67, and AP72 $(200 \mu \mathrm{mol} / \mathrm{L})$ at $37^{\circ} \mathrm{C}$ for 16 hours, followed by determination of TBARS and LOOH. Representative experiment, $n=3$, each performed in triplicate. (C) Soft plaque lipids $(400 \mu \mathrm{g} /$ $\mathrm{mL})$ were incubated with $\mathrm{Hb}(20 \mu \mathrm{mol} / \mathrm{L})$ alone or in the presence of $\mathrm{HSX}^{-}$or decomposed sulfide donors $\mathrm{NaSH}$, GYY4137, AP67, and AP72 $(200 \mu \mathrm{mol} / \mathrm{L})$ at $37^{\circ} \mathrm{C}$ for 16 hours, followed by determination of TBARS and $\mathrm{LOOH}$. Representative experiment, $n=3$, each performed in triplicate. Supplementary Figure 6: polysulfides and decomposed sulfide donors do not prevent $\mathrm{Hb}$-lipid interactions on endothelial cells. (A-B) OxLDL $(200 \mu \mathrm{g} / \mathrm{mL})$ was incubated with $\mathrm{HSX}^{-}$or decomposed sulfide donors NaSH, GYY4137, AP67, and AP72 at the concentration of $200 \mu \mathrm{mol} / \mathrm{L}$ at $37^{\circ} \mathrm{C}$ for 16 hours. HUVECs were treated with the samples for 6 hours then cell viability was determined by MTT assay. Representative experiment, $n=3$, each performed in 8 wells in parallel. OxLDL $(200 \mu \mathrm{g} / \mathrm{mL})$ was incubated with $\mathrm{HSX}^{-}$or decomposed sulfide donors NaSH, GYY4137, AP67, and AP72 at the concentration of $200 \mu \mathrm{mol} / \mathrm{L}$ at $37^{\circ} \mathrm{C}$ for 16 hours. (C) HUVECs were treated to LDL samples $(50 \mu \mathrm{g} / \mathrm{mL})$ for 8 hours. HO-1 protein expression was determined by Western blotting. Representative experiment, $n=3$. Relative densitometry was determined with ImageJ software. (D) $\mathrm{Hb}(10 \mu \mathrm{mol} / \mathrm{L})$ was incubated with $\mathrm{H}_{2} \mathrm{O}_{2}$ ( $50 \mu \mathrm{mol} / \mathrm{L})$ in the presence or absence of $\mathrm{HSX}^{-}$or decomposed sulfide donors NaSH, GYY4137, AP67, and AP72 $(200 \mu \mathrm{mol} / \mathrm{L})$ at $37^{\circ} \mathrm{C}$ for 90 minutes. HUVECs were exposed to the obtained $\mathrm{Hb}$ samples for 8 hours and VCAM-1 expression was determined by Western blotting. Representative experiment, $n=3$. Relative densitometry was determined with Image software. (Supplementary Materials)

\section{References}

[1] A. C. Barger, R. Beeuwkes 3rd, L. L. Lainey, and K. J. Silverman, "Hypothesis: vasa vasorum and neovascularization of human coronary arteries - a possible role in the pathophysiology of atherosclerosis," The New England Journal of Medicine, vol. 310, no. 3, pp. 175-177, 1984.

[2] H. C. Stary, A. B. Chandler, R. E. Dinsmore et al., "A definition of advanced types of atherosclerotic lesions and a histological classification of atherosclerosis. A report from the Committee on Vascular Lesions of the Council on Arteriosclerosis, American Heart Association," Circulation, vol. 92, no. 5, pp. 1355-1374, 1995.

[3] F. D. Kolodgie, H. K. Gold, A. P. Burke et al., "Intraplaque hemorrhage and progression of coronary atheroma," The New England Journal of Medicine, vol. 349, no. 24, pp. 23162325, 2003.

[4] W. Li, M. Ostblom, L. H. Xu et al., "Cytocidal effects of atheromatous plaque components: the death zone revisited," The FASEB Journal, vol. 20, no. 13, pp. 2281-2290, 2006.

[5] J. B. Michel, J. L. Martin-Ventura, A. Nicoletti, and B. Ho-Tin-Noé, "Pathology of human plaque vulnerability: mechanisms and consequences of intraplaque haemorrhages," Atherosclerosis, vol. 234, no. 2, pp. 311-319, 2014.

[6] J. B. Michel, R. Virmani, E. Arbustini, and G. Pasterkamp, "Intraplaquehaemorrhages as the trigger of plaque vulnerability," European Heart Journal, vol. 32, no. 16, pp. 1977-1985, 2011.

[7] X. M. Yuan, U. T. Brunk, and A. G. Olsson, "Effects of iron- and hemoglobin-loaded human monocyte-derived 
macrophages on oxidation and uptake of LDL," Arteriosclerosis, Thrombosis, and Vascular Biology, vol. 15, no. 9, pp. 13451351, 1995.

[8] X. M. Yuan, W. Li, A. G. Olsson, and U. T. Brunk, "Iron in human atheroma and LDL oxidation by macrophages following erythrophagocytosis," Atherosclerosis, vol. 124, no. 1, pp. 61-73, 1996.

[9] X. M. Yuan, A. G. Olsson, and U. T. Brunk, "Macrophage erythrophagocytosis and iron exocytosis," Redox Report, vol. 2, no. 1, pp. 9-17, 1996.

[10] E. Nagy, J. W. Eaton, V. Jeney et al., "Red cells, hemoglobin, heme, iron, and atherogenesis," Arteriosclerosis, Thrombosis, and Vascular Biology, vol. 30, no. 7, pp. 1347-1353, 2010.

[11] L. Potor, E. Banyai, G. Becs et al., "Atherogenesis may involve the prooxidant and proinflammatory effects of ferryl hemoglobin," Oxidative Medicine and Cellular Longevity, vol. 2013, Article ID 676425, 13 pages, 2013.

[12] V. Jeney, G. Balla, and J. Balla, "Red blood cell, hemoglobin and heme in the progression of atherosclerosis," Frontiers in Physiology, vol. 5, p. 379, 2014.

[13] J. Balla, H. S. Jacob, G. Balla, K. Nath, J. W. Eaton, and G. M. Vercellotti, "Endothelial-cell heme uptake from heme proteins: induction of sensitization and desensitization to oxidant damage," Proceedings of the National Academy of Sciences of the United States of America, vol. 90, no. 20, pp. 9285-9289, 1993.

[14] V. Jeney, J. Balla, A. Yachie et al., "Pro-oxidant and cytotoxic effects of circulating heme," Blood, vol. 100, no. 3, pp. 879887, 2002.

[15] G. Silva, V. Jeney, A. Chora, R. Larsen, J. Balla, and M. P. Soares, "Oxidized hemoglobin is an endogenous proinflammatory agonist that targets vascular endothelial cells," The Journal of Biological Chemistry, vol. 284, no. 43, pp. 2958229595, 2009.

[16] S. Mani, A. Untereiner, L. Wu, and R. Wang, "Hydrogen sulfide and the pathogenesis of atherosclerosis," Antioxidants \& Redox Signaling, vol. 20, no. 5, pp. 805-817, 2014.

[17] Y. Wang, X. Zhao, H. Jin et al., "Role of hydrogen sulfide in the development of atherosclerotic lesions in apolipoprotein E knockout mice," Arteriosclerosis, Thrombosis, and Vascular Biology, vol. 29, no. 2, pp. 173-179, 2009.

[18] S. Mani, H. Li, A. Untereiner et al., "Decreased endogenous production of hydrogen sulfide accelerates atherosclerosis," Circulation, vol. 127, no. 25, pp. 2523-2534, 2013.

[19] M. K. Chitnis, Y. F. Njie-Mbye, C. A. Opere, M. E. Wood, M. Whiteman, and S. E. Ohia, "Pharmacological actions of the slow release hydrogen sulfide donor GYY4137 on phenylephrine-induced tone in isolated bovine ciliary artery," Experimental Eye Research, vol. 116, pp. 350-354, 2013.

[20] M. Whiteman, L. Li, P. Rose, C. H. Tan, D. B. Parkinson, and P. K. Moore, "The effect of hydrogen sulfide donors on lipopolysaccharide-induced formation of inflammatory mediators in macrophages," Antioxidants \& Redox Signaling, vol. 12, no. 10, pp. 1147-1154, 2010.

[21] C. C. Winterbourn, "[26] Oxidative reactions of hemoglobin," Methods in Enzymology, vol. 186, pp. 265-272, 1990.

[22] E. Nagy, V. Jeney, A. Yachie et al., "Oxidation of hemoglobin by lipid hydroperoxide associated with low-density lipoprotein (LDL) and increased cytotoxic effect by LDL oxidation in heme oxygenase-1 (HO-1) deficiency," Cellular and Molecular Biology, vol. 51, no. 4, pp. 377-385, 2005.
[23] N. Gilboa-Garber, "Direct spectrophotometric determination of inorganic sulfide in biological materials and in other complex mixtures," Analytical Biochemistry, vol. 43, no. 1, pp. 129-133, 1971.

[24] A. D. Ang, A. Konigstorfer, G. I. Giles, and M. Bhatia, "Measuring free tissue sulfide," Advances in Biological Chemistry, vol. 2, no. 4, pp. 360-365, 2012.

[25] G. Balla, H. S. Jacob, J. W. Eaton, J. D. Belcher, and G. M. Vercellotti, "Hemin: a possible physiological mediator of low density lipoprotein oxidation and endothelial injury," Arteriosclerosis, Thrombosis, and Vascular Biology, vol. 11, no. 6, pp. 1700-1711, 1991.

[26] B. J. Reeder, "The redox activity of hemoglobins: from physiologic functions to pathologic mechanisms," Antioxidants \& Redox Signaling, vol. 13, no. 7, pp. 1087-1123, 2010.

[27] L. J. Deterding, D. C. Ramirez, J. R. Dubin, R. P. Mason, and K. B. Tomer, "Identification of free radicals on hemoglobin from its self-peroxidation using mass spectrometry and immuno-spin trapping: observation of a histidinyl radical," The Journal of Biological Chemistry, vol. 279, no. 12, pp. 11600-11607, 2004.

[28] C. E. Cooper, D. J. Schaer, P. W. Buehler et al., "Haptoglobin binding stabilizes hemoglobin ferryl iron and the globin radical on tyrosine $\beta 145$," Antioxidants \& Redox Signaling, vol. 18, no. 17, pp. 2264-2273, 2013.

[29] M. K. Muellner, S. M. Schreier, H. Laggner et al., "Hydrogen sulfide destroys lipid hydroperoxides in oxidized LDL," The Biochemical Journal, vol. 420, no. 2, pp. 277-281, 2009. 


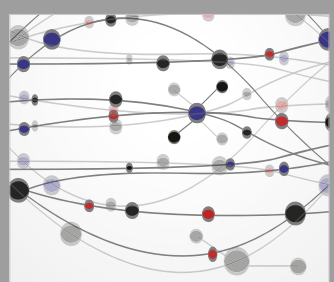

The Scientific World Journal
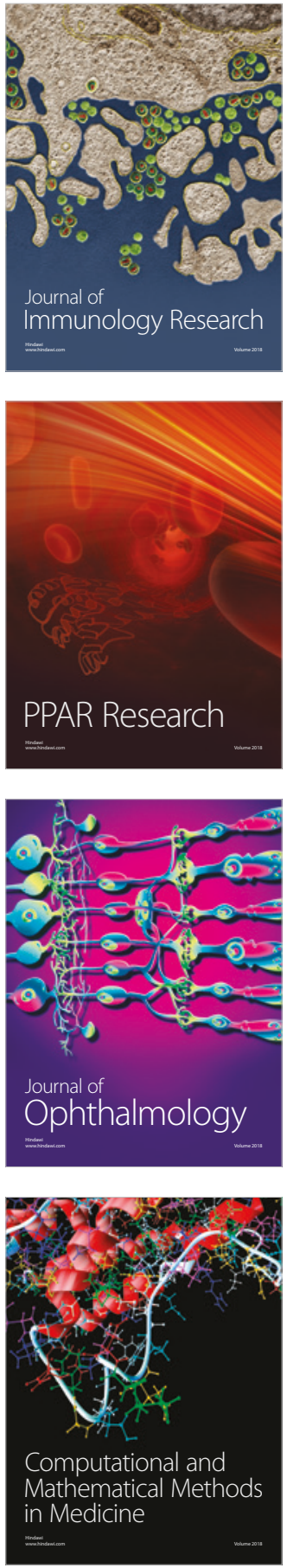

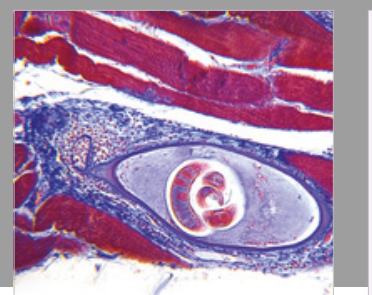

Gastroenterology Research and Practice

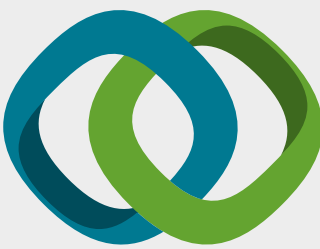

\section{Hindawi}

Submit your manuscripts at

www.hindawi.com
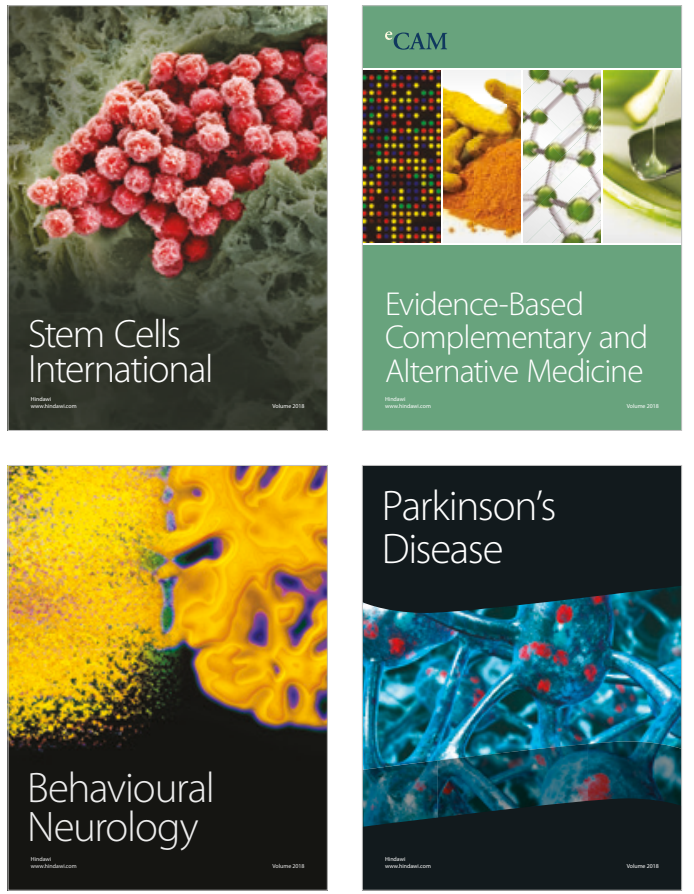

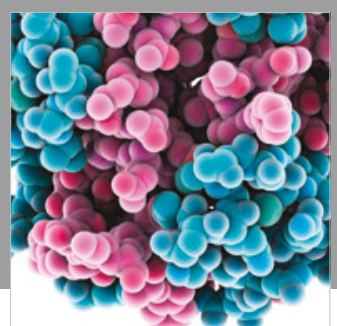

ournal of

Diabetes Research

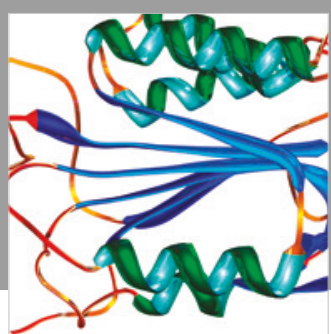

Disease Markers
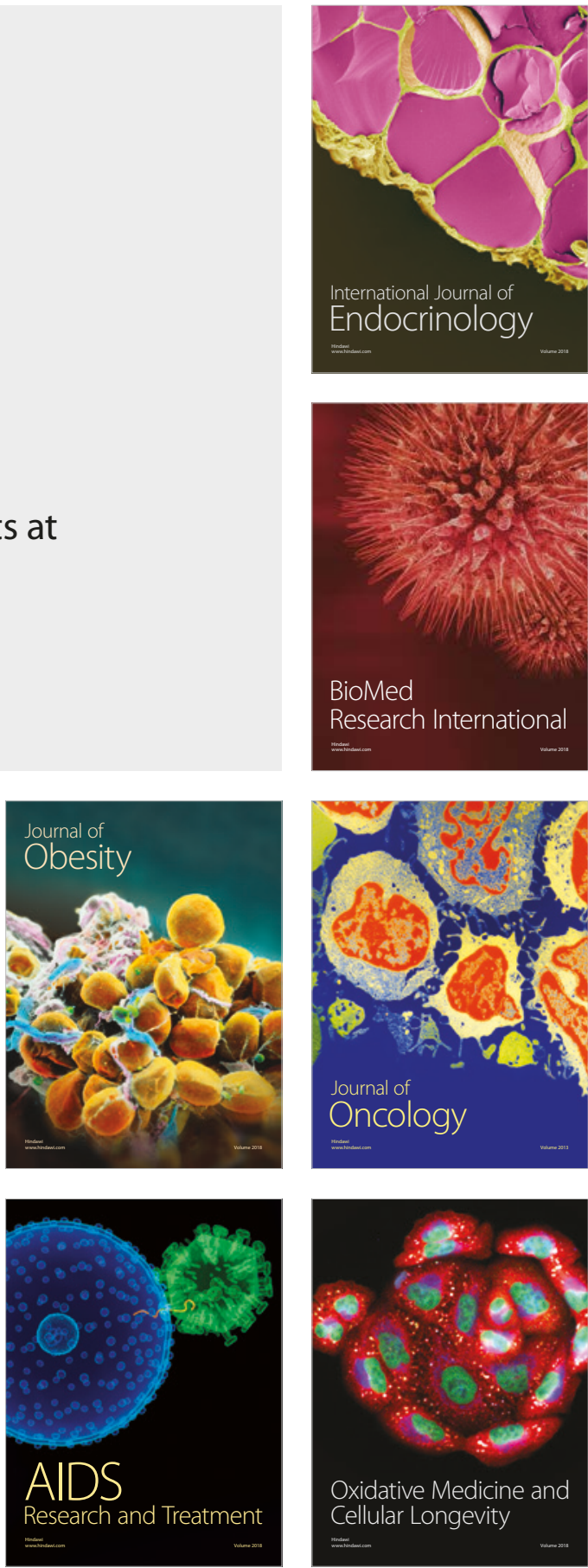